Hydrology and Earth System Sciences, 9, 243-261, 2005

www.copernicus.org/EGU/hess/hess/9/243/

SRef-ID: 1607-7938/hess/2005-9-243

European Geosciences Union

\title{
Rainfall-runoff modelling in a catchment with a complex groundwater flow system: application of the Representative Elementary Watershed (REW) approach
}

\author{
G. P. Zhang and H. H. G. Savenije \\ Water Resources Section, Faculty of Civil Engineering and Applied Geosciences, Delft University of Technology, Stevinweg \\ 1, P.O. Box 5048, 2600 GA Delft, The Netherlands
}

Received: 7 March 2005 - Published in Hydrology and Earth System Sciences Discussions: 12 May 2005

Revised: 11 August 2005 - Accepted: 2 September 2005 - Published: 21 September 2005

\begin{abstract}
Based on the Representative Elementary Watershed (REW) approach, the modelling tool REWASH (Representative Elementary WAterShed Hydrology) has been developed and applied to the Geer river basin. REWASH is deterministic, semi-distributed, physically based and can be directly applied to the watershed scale. In applying REWASH, the river basin is divided into a number of sub-watersheds, so called REWs, according to the Strahler order of the river network. REWASH describes the dominant hydrological processes, i.e. subsurface flow in the unsaturated and saturated domains, and overland flow by the saturation-excess and infiltration-excess mechanisms. The coupling of surface and subsurface flow processes in the numerical model is realised by simultaneous computation of flux exchanges between surface and subsurface domains for each REW. REWASH is a parsimonious tool for modelling watershed hydrological response. However, it can be modified to include more components to simulate specific processes when applied to a specific river basin where such processes are observed or considered to be dominant. In this study, we have added a new component to simulate interception using a simple parametric approach. Interception plays an important role in the water balance of a watershed although it is often disregarded. In addition, a refinement for the transpiration in the unsaturated zone has been made. Finally, an improved approach for simulating saturation overland flow by relating the variable source area to both the topography and the groundwater level is presented. The model has been calibrated and verified using a 4-year data set, which has been split into two for calibration and validation. The model performance has been assessed by multi-criteria evaluation. This work represents
\end{abstract}

Correspondence to: G. P. Zhang

(g.p.zhang@ citg.tudelft.nl) a complete application of the REW approach to watershed rainfall-runoff modelling in a real watershed. The results demonstrate that the REW approach provides an alternative blueprint for physically based hydrological modelling.

\section{Introduction}

Hydrological models are important and necessary tools for water and environmental resources management. Demands from society on the predictive capabilities of such models are becoming higher and higher, leading to the need of enhancing existing models and even of developing new theories. Existing hydrological models can be classified into three types, namely, 1) empirical models (black-box models); 2) conceptual models; and 3) physically based models. To address the question of how land use change and climate change affect hydrological (e.g. floods) and environmental (e.g. water quality) functioning, the model needs to contain an adequate description of the dominant physical processes.

Following the blueprint proposed by Freeze and Harlan (1969), a number of distributed and physically based models have been developed, among which are the well-known SHE (Abbott et al., 1986a, b), MIKE SHE (Refsgaard and Storm, 1995), IHDM (Beven et al., 1987; Calver and Wood, 1995), and THALES (Grayson et al., 1992a) models. These models are able to produce variations in state-variables over space and time, and representations of internal flow processes. It is assumed that the parameter values in the equations of such models can be obtained from measurements as long as the models are used at the appropriate scale. Physicallybased distributed models particularly aim at predicting the effects of land-use change. However, considerable debate on

(C) 2005 Author(s). This work is licensed under a Creative Commons License. 
both the advantages and disadvantages of such models has arisen along with research and applications of those models (see, e.g. Beven 1989, 1996a, b, 2002; Grayson et al., 1992b; Refsgaard et al., 1996; O'Connell and Todini, 1996). In general, such models are very data-intensive and timeconsuming when applied in a fully distributed manner. In applications, the model scale is generally much larger than the scale of parameter measurements. Therefore, "effective" parameter values have to be adopted in model applications and thus calibration becomes inevitable for physically based models. This leads to the difficulty of parameter identification and the equifinality problem (Beven, 1993, 1996c; Savenije, 2001).

Conceptual models form by far the largest group of hydrological models that have been developed by the hydrological community and which are most often applied in operational practice. Among those are SAC-SMA (Burnash et al., 1973; Burnash, 1995), HBV (Bergström and Forsman, 1973; Bergström, 1995), and LASCAM (Sivapalan et al., 1996). Most conceptual models are spatially lumped, neglecting the spatial variability of the state variables and parameters. To improve the potential for making use of spatially distributed data, some lumped conceptual models have been extended to be distributed or semi-distributed. Examples are the HBV-96 model (Lindström et al., 1997), TOPMODEL (Beven, 1995) and the ARNO model (Todini, 1996). Parameters of this type of models, however, either lack physical meaning or cannot be measured in the field. Parameter identifiability and equifinality are the major concerns of such models.

In view of all these different types of modelling approaches, one can notice that there is no commonly accepted general framework for describing the hydrological response directly applicable at watershed scale. To fill this gap, Reggiani et al. $(1998,1999)$ made an attempt to derive a unifying framework for modelling watershed response, which has been named the Representative Elementary Watershed (REW) approach. This theory applies global balance laws of mass and momentum and yields a system of coupled nonlinear ordinary differential equations at the REW scale, governing flows between different sub-domains of a REW. To demonstrate the applicability of the REW approach, Reggiani et al. (2000) investigated the long-term water balance of a single hypothetical REW using the equations in nondimensional form. In that work, only hill-slope subsurface responses, i.e. flows in the unsaturated and saturated zones were considered. In succession, Reggiani et al. (2001) applied the REW approach to a natural watershed but only focusing on the response of the channel network. They provided the theoretical development of the REW approach and demonstrated that the approach can provide a framework for an alternative blueprint for modelling watershed response (Beven, 2002; Reggiani and Schellekens, 2003).

Parallel to theory formulation, much work has been done to apply the REW approach towards the development of watershed models. Zhang et al. (2003, 2004a, b, 2005a) and
Reggiani and Rientjes (2005) reported on advances of the research in this regard. However, as Beven (2002) pointed out while discussing about the REW approach, one should recognise that the balance equations alone are indeterminate, and additional functional relationships associated with the simplifying assumptions (i.e. the so called constitutive relationships), for the fluxes within and between REWs, are crucial to the closure of the system. We would like to stress this issue as the closure problem. Lee et al. (2005) and Zehe et al. (2005) presented comprehensive discussions in this regard. One can understand that developing closure relations is in fact the way of parameterisation. Thus, proper closure relations are keys to a successful application of the approach. Zhang et al. (2005a) made a step towards a better model parameterisation and showed encouraging results when applied to a temperate humid watershed. Meanwhile, it is obvious that an incomplete description of hydrological processes inevitably results in poor performance and leads to erroneous results. For instance, as pointed out by Savenije (2004, 2005), neglecting interception can introduce significant errors in other parameters. Moreover, previous research on the REW approach to modelling of actual catchments highlighted the need for significant improvements. Therefore, this paper reports on the current state of development of the REW approach within our research framework.

In this work, the numerical model REWASH has been developed based on the original code developed by $P$. Reggiani and reflected in the application presented in Reggiani and Rientjes (2005). REWASH includes the process of interception and a modified transpiration scheme for the unsaturated zone. The model has been applied to the Geer river basin and the model performance has been evaluated through calibration and verification procedures. Model calibration and verification have been carried out through a combination of manual and automatic calibration, and a split-sample test. Sensitivity analysis has been performed to examine model behaviour and identify the most important parameters. Modelling results show that the hydrographs can be well reproduced and the model is able to simulate the watershed response at a large spatial scale in a lumped fashion while the parameters are kept physically meaningful. However, there is still considerable scope for improvement (e.g. Zhang et al., 2005b). It is realised that closure relations need to be watershed-specific, depending on the dominant mechanisms and data availability.

\section{Mathematical representation of the hydrological pro- cesses}

\subsection{The concept of the REW approach}

In the REW approach, a river basin is spatially divided into a number of sub-watersheds, so-called REWs. The REW preserves the basic structure and functional components of 
a watershed (hill-slopes and channels, Fig. 1). The discretisation is based on the analysis of the basin topography using the Strahler stream order system. The topographical boundaries of REWs coincide with their surface water divides, thus REWs are naturally interconnected through the stream networks as well as through the subsurface flow paths in terms of water flux exchanges. While determining the size of individual REWs and their sub-domains, each REW is implicitly defined in three dimensions and delimited externally by a prismatic mantle.

The volumetric entities of a REW contain flow domains commonly encountered or described within a watershed: 1) the unsaturated flow domain, 2) the saturated flow domain, 3 ) the saturation-excess overland flow domain, 4) the concentrated overland flow domain (or the infiltration-excess overland flow domain), and 5) the river channel. Hydrological processes in these domains are characterised by different temporal scales. For instance, overland flow has a time scale of minutes to hours, while saturated groundwater flow has months to years (Blöschl and Sivapalan, 1995).

In the REW approach, averaged balance equations of mass and momentum for each flow domain were derived (Reggiani et al., 1998, 1999), resulting in a set of non-linear ordinary differential equations (ODEs) which no longer contain any spatial information below the REW scale. In contrast to gridbased methods applied in most distributed model approaches (e.g. Abbott et al., 1986a, b), the REW approach uses the sub-watersheds (REWs) as "cells", the basic discretisation units on which the ODEs are solved.

The general form of the ODEs reads:

$\frac{d \phi}{d t}=\sum_{i} e_{\phi i}+s$

where $\phi$ represents a generic thermodynamic property such as mass or momentum. $e_{\phi i}$ stands for a generic exchange term of $\phi$ and $s$ is a grouped sink/source term for the domain in question. This form can be extended to include terms for more complex flow phenomena, such as multi-phase flow and pollutants transport. As we know, the conservation equation itself alone is not a closed system. The exchange term $e_{\phi i}$ is unknown and needs to be specified. This term has to be expressed in a form that relates the state variables to other resolved variables. This comes to the problem of finding proper closure relations for the balance equations, as touched upon in the introduction. Closure relations for process descriptions at the catchment-scale, other than the point-scale or the REV (representative elementary volume) scale, are not readily available. However, after rigorous theoretical derivation, REW-scale equations for: Darcy's law, Manning's law, and the Saint-Venant equations have been obtained and employed in our model, which are valid for subsurface, overland and channel flow, respectively. The relations of these equations to the flux terms are summarised in Table 1 of the following section.

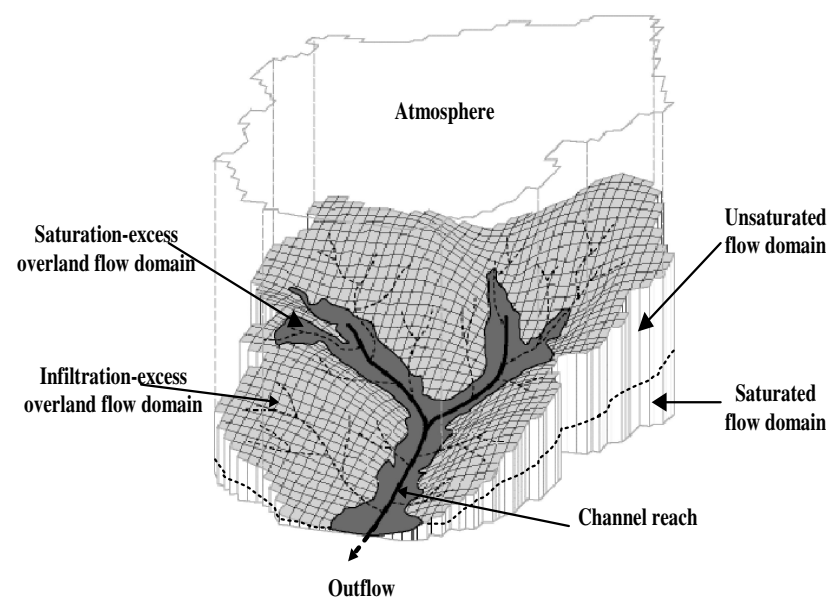

Fig. 1. A 3-D view of the volume comprising a single REW (modified from Reggiani and Schellekens, 2003).

\subsection{Description of the numerical model}

In many hydrological models or model approaches, interception is neglected even though it is the first process in the chain of interlinked rainfall-runoff processes (Savenije, 2004). By ignoring this process, errors are introduced that propagate into the subsequent processes simulated (particularly into the soil moisture and groundwater flow process) and into the water balance regime in the different stores of a watershed, although sometimes they may not be detected by only looking at the single integral output: the simulated stream discharge. In the initial stage of the development and application of the REW approach, interception was not explicitly considered. Bearing this in mind, we have added a component in this model using a simple parametric approach to account for the interception effect. In addition, in line with the work by Zhang et al. (2003, 2004a, b), a refinement for sub-grid variability of soil properties in the soil column has been taken into account. Moreover, a new approach to determine the saturated overland area has been introduced. Based on these modifications, the water balance equations for the different flow domains and governing equations for the various flow processes are described below.

\subsubsection{Water balance equations for flow domains}

Mass conservation is the first principle ruling water flux exchanges in a watershed system. In accordance with observation and understanding of the flow processes in the terrestrial system, a REW is sub-discretised vertically into various flow domains. Figure 2 illustrates the schematised profile of a REW with the different flow domains, their geometric quantities and the water flux exchange terms. With reference to Fig. 2, the water balance equations for each flow domain are given as follows. 


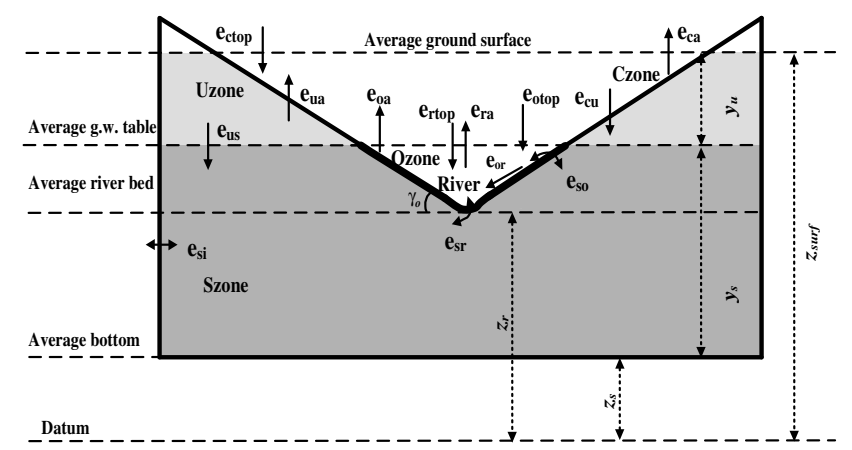

Fig. 2. Schematised cross-sectional profile of a REW. Czone, Ozone, Uzone, Szone and River stand for the infiltration-excess overland flow domain, the saturation-excess overland flow domain, the unsaturated flow domain, the saturated flow domain and the River flow domain, respectively. $e_{c t o p}, e_{c u}, e_{c a}$ etc. are flux terms. $y_{u}, y_{s}$ are stock variables, and $z_{s}, z_{r}, z_{\text {surf }}$ and $\gamma_{o}$ are average geometric quantities of the REW.

Infiltration-excess overland flow domain

$\frac{d S_{c}}{d t}=e_{c t o p}+e_{c a}+e_{c u}+e_{c o}$

where $S_{c}(\mathrm{M})$ is the storage of the infiltration-excess overland flow domain. The fluxes $e_{c t o p}\left(\mathrm{MT}^{-1}\right), e_{c a}\left(\mathrm{MT}^{-1}\right)$, $e_{c u}\left(\mathrm{MT}^{-1}\right)$ and $e_{c o}\left(\mathrm{MT}^{-1}\right)$ are the rainfall on the surface of this zone, the evaporation from interception on this zone, the infiltration to the saturated zone and the transfer towards the saturation-excess flow domain, respectively. Since we are applying this model approach to a humid temperate river basin where the saturation-excess flow is dominant, the infiltrationexcess overland flow is negligible, thus $e_{c o}$ is kept zero.

Saturation excess overland flow domain

$\frac{d S_{o}}{d t}=e_{o t o p}+e_{o a}+e_{o s}+e_{o r}+e_{o c}$

where $S_{o}(\mathrm{M})$ is the storage of the saturation-excess overland flow domain. The fluxes $e_{o t o p}\left(\mathrm{MT}^{-1}\right), e_{o a}\left(\mathrm{MT}^{-1}\right), e_{o s}$ $\left(\mathrm{MT}^{-1}\right), e_{o r}\left(\mathrm{MT}^{-1}\right)$ and $e_{o c}\left(\mathrm{MT}^{-1}\right)$ are the rainfall on the surface of this zone, the evaporation from this zone, the exchange between this zone and the saturated flow zone, the transfer to the river channel, and the exchange between this zone and the infiltration-excess flow zone, respectively. For the same reason stated above, $e_{o c}$ is ignored.

Unsaturated subsurface flow domain

$\frac{d S_{u}}{d t}=e_{u a}+e_{u c}+e_{u s}$

where $S_{u}(\mathrm{M})$ is the storage of the unsaturated flow domain. The fluxes $e_{u a}\left(\mathrm{MT}^{-1}\right), e_{u c}\left(\mathrm{MT}^{-1}\right)$, and $e_{u s}\left(\mathrm{MT}^{-1}\right)$ are the transpiration, the infiltration and the percolation.
Saturated subsurface flow domain

$\frac{d S_{s}}{d t}=e_{s u}+e_{s o}+e_{s r}+e_{s i}+e_{s a}$

where $S_{s}(\mathrm{M})$ is the storage of the saturated flow domain. The fluxes $e_{s u}\left(\mathrm{MT}^{-1}\right)$ and $e_{s o}\left(\mathrm{MT}^{-1}\right)$ are the counterparts of $e_{u s}\left(\mathrm{MT}^{-1}\right)$ and $e_{o s}\left(\mathrm{MT}^{-1}\right)$ in Eqs. (3) and (4), respectively; $e_{s r}\left(\mathrm{MT}^{-1}\right), e_{s i}\left(\mathrm{MT}^{-1}\right)$ and $e_{s a}\left(\mathrm{MT}^{-1}\right)$ are the exchange between the saturated zone and river channel, the exchange with the neighbouring REWs (if any) and the groundwater abstraction (if any).

River channel

$\frac{d S_{r}}{d t}=e_{r t o p}+e_{r a}+e_{r s}+e_{r o}+e_{r i n}+e_{r o u t}$

where $S_{r}(\mathrm{M})$ is the storage of the river channel segment within the REW under investigation. The fluxes $e_{r t o p}$ $\left(\mathrm{MT}^{-1}\right), e_{r a}\left(\mathrm{MT}^{-1}\right), e_{\text {rin }}\left(\mathrm{MT}^{-1}\right)$ and $e_{\text {rout }}\left(\mathrm{MT}^{-1}\right)$ are the rainfall on the channel water surface, the evaporation from the water surface, the water coming from upstream channel segment(s) and the flow out of the segment of the REW in question, respectively. The fluxes $e_{r s}\left(\mathrm{MT}^{-1}\right), e_{r o}\left(\mathrm{MT}^{-1}\right)$ are the counterparts of $e_{s r}$ and $e_{o r}$ in Eqs. (3) and (5), respectively.

The functional relationships to quantify the flux terms presented in these equations are described in the following section.

\subsubsection{Parameterised governing equations for rainfall-runoff processes}

Rainfall input

The rainfall flux on a REW is partitioned into three portions in terms of the area that captures the rainfall, which are $e_{c t o p}$, the rainfall flux to the infiltration-excess overland flow area, $e_{\text {otop }}$ to the saturation overland flow area and $e_{\text {rtop }}$ to the river channel, respectively. They are described by

$$
\left\{\begin{array}{l}
e_{\text {ctop }}=\rho i A \omega_{c} \\
e_{\text {otop }}=\rho i A \omega_{o} \\
e_{\text {rtop }}=\rho i l_{r} w_{r}
\end{array}\right.
$$

where $\rho\left(\mathrm{ML}^{-3}\right)$ is the water density; $A\left(\mathrm{~L}^{2}\right)$ the horizontally projected surface area of the REW; $i\left[\mathrm{LT}^{-1}\right]$ the precipitation intensity. $\omega_{c}(-)$ and $\omega_{o}(-)$ are the infiltration-excess and the saturation-excess overland flow area fractions, respectively. $l_{r}(\mathrm{~L})$ and $w_{r}(\mathrm{~L})$ are the length and the average width of the channel.

Interception

For modelling the detailed dynamics of the interception process, a complex descriptor derived from mass and energy 
balance principles would be necessary. In that case, an additional model domain describing the process would be desirable and additional parameters such as the leaf area index (LAI) would be required. To keep the model as parsimonious as possible, we chose a simple approach. We assume that interception is taking place in the infiltration-excess flow domain. Considering a storage capacity of the interception media (e.g. tree leaves, undergrowth, forest floor and surface) and assuming that the intercepted water will be eventually evaporated within a day, the interception flux is determined by

$e_{c a}=\min \left(i, i_{d c}\right) \rho A \omega_{c}$

where $i_{d c}\left(\mathrm{LT}^{-1}\right)$ is the daily interception threshold.

Infiltration

Similar to the approach of Reggiani et al. (2000), the infiltration capacity can be computed by

$f=\frac{K_{s u}}{\Lambda_{u}}\left(\frac{1}{2} y_{u}+h_{c}\right)$

where $f\left(\mathrm{LT}^{-1}\right)$ is the infiltration capacity; $K_{s u}\left(\mathrm{LT}^{-1}\right)$ the vertical saturated hydraulic conductivity of the unsaturated zone; $\Lambda_{u}$ (L) the length over which the wetting front is reached; $y_{u}(\mathrm{~L})$ the averaged unsaturated zone depth; and $h_{c}$ [L] the capillary pressure head, which is described using the Brooks and Corey (1964) soil water retention model:

$h_{c}=\psi_{b}\left(\frac{\theta_{u}}{\varepsilon_{u}}\right)^{-1 / \mu}$

where $\psi_{b}(\mathrm{~L})$ is the air entry pressure head; $\theta_{u}(-)$ and $\varepsilon_{u}(-)$ are the soil moisture content and the effective soil porosity of the unsaturated zone, respectively; $\mu(-)$ is the soil pore size distribution index.

It is reasonable to assume that all rainfall reaching the ground surface infiltrates into the soil when it is climate controlled, i.e. the rainfall intensity is lower than the infiltration capacity. Consequently, the actual infiltration flux is estimated by

$e_{c u}=\min \left[\left(i-i_{d c}\right), f\right] \rho \omega_{c} A$

where $\omega_{c}(-)$ is the area fraction of the infiltration-excess overland flow zone, which is equal to the unsaturated zone area fraction. The remaining symbols are the same as in the above equations. The first term of the right-hand side in Eq. (11) calculates the effective rainfall intensity.
Evaporation/transpiration

$$
\left\{\begin{aligned}
e_{u a}= & \min \left[1.0,\left(2 \frac{\theta_{u}}{\varepsilon_{u}}\right)\right]\left[e_{p}-\min \left(i, i_{d c}\right)\right] \\
& \rho \omega_{u} A \text { (for Uzone) } \\
e_{o a}= & e_{p} \rho \omega_{o} A \text { (for Ozone) } \\
e_{r a}= & e_{p} \rho l_{r} w_{r} \text { (for Rzone) }
\end{aligned}\right.
$$

where $e_{p}\left(\mathrm{LT}^{-1}\right)$ is the potential evaporation. One can see that when the soil moisture of the unsaturated zone is less than $50 \%$ of the soil porosity, it is assumed that the evaporation from the unsaturated zone is water constrained, leading to a reduced evaporation rate. A linear reduction function is used here, which agrees with the procedure generally used in agricultural engineering (e.g. Rijtema and Aboukhaled, 1975; Doorenbos and Kassam, 1979).

Percolation/capillary rise

$e_{u s}=\alpha_{u s} \rho \omega_{c} A \frac{K_{u}}{y_{u}}\left[\left(\frac{1}{2}-\frac{\theta_{u}}{\varepsilon_{u}}\right) y_{u}+h_{c}\right]$

where $\alpha_{u s}(-)$ is the scaling factor for this flux exchange term. $K_{u}\left(\mathrm{LT}^{-1}\right)$ is the effective hydraulic conductivity for the unsaturated zone, which is a function of the saturation $\left(\theta_{u} / \varepsilon_{u}\right)$ of the unsaturated zone. As an additional condition, percolation is set to take place only if $\theta_{u}$ is greater than the field capacity $\theta_{f} . K_{u}$ can be determined by the following relationship in Brooks and Corey (1964) approach:

$$
\begin{aligned}
& K_{u}=K_{s u}\left(\frac{\theta_{u}}{\varepsilon_{u}}\right)^{\lambda} \\
& \lambda=3+\frac{2}{\mu}
\end{aligned}
$$

where $\lambda$ is the soil pore-disconnectedness index.

Base flow

$e_{s r}=\frac{\rho K_{s r} l_{r} P_{r}}{\Lambda_{r}}\left(h_{r}-h_{s}\right)$

where $K_{s r}\left(\mathrm{LT}^{-1}\right)$ and $P_{r}(\mathrm{~L})$ are the hydraulic conductivity for the river bed transition zone and the wetted perimeter of the river cross section, respectively. $\Lambda_{r}(\mathrm{~L})$ is the depth of transition layer of the river bed. $h_{r}(\mathrm{~L})$ and $h_{s}(\mathrm{~L})$ are the total hydraulic heads in the river channel and the saturated zone, respectively.

Exfiltration to the surface

$e_{s o}=\frac{\rho K_{s s} \omega_{o} A}{\Lambda_{s} \cos \gamma_{o}}\left(h_{s}-h_{o}\right)$ 
where $K_{s s}\left(\mathrm{LT}^{-1}\right)$ and $\omega_{o}(-)$ are the saturated hydraulic conductivity for the saturated zone and the area fraction of the saturated overland flow zone, respectively. $h_{s}(\mathrm{~L})$ and $h_{o}(\mathrm{~L})$ are respectively the total hydraulic head in the saturated zone and the saturated overland flow zone. $\Lambda_{s}(\mathrm{~L})$ is a typical length over which the head difference between the saturated zone and the saturated overland zone is dissipated. $\gamma_{o}$ is the average slope angle of the seepage face in radian.

Regional groundwater flow

$e_{s i}=\alpha_{s i} \rho\left(h_{s}-h_{s i}\right)$

where $e_{s i}$ is the flux exchange between the saturated zones of the REW in question and its $i$ th neighbouring REW; $h_{s}$ (L) and $h_{s i}$ (L) are the total hydraulic heads of the saturated zones of the two neighbouring REWs, respectively. $\alpha_{s i}\left(\mathrm{~L}^{2} \mathrm{~T}^{-1}\right)$ is a lumped scaling factor involving the contour length of the mantle segment of the $i$ th REW, the harmonic mean of the saturated hydraulic conductivity over the two REWs, etc. If there is no groundwater connection between REWs or if the groundwater level has a horizontal gradient at the water divide, then $\alpha_{s i}$ is set to zero.

Lateral overland flow to channel

$e_{o r}=2 \rho y_{o} l_{r} \frac{1}{n}\left(\sin \gamma_{o}\right)^{1 / 2}\left(y_{o}\right)^{2 / 3}$

where $y_{o}(\mathrm{~L})$ is the average depth of the flow sheet on the surface of the overland flow domain; and $n\left(\mathrm{TL}^{-1 / 3}\right)$ the Manning roughness coefficient.

Channel flow

$e_{\text {rin }}=\rho \sum_{i} \frac{1}{2} m_{r i}\left(v_{r}+v_{r i}\right)$

$e_{\text {rout }}=\rho \frac{1}{2} m_{r}\left(v_{r}+v_{r j}\right)$

$v_{r}=$

$\sqrt{\frac{8 g}{P_{r} l_{r} \xi}\left[m_{r} l_{r} \sin \gamma_{r}+\sum_{i} \frac{1}{4} y_{r}\left(m_{r}+m_{r i}\right)-\frac{1}{4} y_{r}\left(m_{r}+m_{r j}\right)\right]}$

where $m_{r}\left(\mathrm{~L}^{2}\right), m_{r i}\left(\mathrm{~L}^{2}\right)$ and $m_{r j}\left(\mathrm{~L}^{2}\right)$ are the average crosssectional area of the channel segment under study, of the $i$ th inflow channel and of the outflow channel, respectively; $v_{r}\left(\mathrm{LT}^{-1}\right), v_{r i}\left(\mathrm{LT}^{-1}\right)$ and $v_{r j}\left(\mathrm{LT}^{-1}\right)$ are the flow velocities within the channel segment under study, and of the inflow and outflow channels, respectively; $\xi(-)$ is the average Darcy-Weisbach friction factor and $g\left(\mathrm{LT}^{-2}\right)$ is the gravitational acceleration; $\gamma_{r}(-)$ is the average slope angle of the river channel and $y_{r}(\mathrm{~L})$ is the water depth of the channel under study.

To summarise the parameterisation of the mass balance equations, Table 1 provides a clear presentation of the flux terms and their closure functions.
2.2.3 Additional functional relationships for the closure of the water balance equations

Zhang et al. (2004b, 2005a) proposed an expression for the saturation overland flow area fraction, which has the following form:

$\left\{\begin{array}{l}\omega_{o}=\alpha_{s f}\left(\frac{y_{s}+z_{s}-z_{r}}{z_{s u r f}-z_{r}}\right)^{\tan \gamma_{o}} \\ \omega_{o}=0\left(\text { if } y_{s}+z_{s}<z_{r}\right)\end{array}\right.$ if $\left.y_{s}+z_{s} \geq z_{r}\right)$

Therefore,

$\frac{d \omega_{o}}{d t}=\alpha_{s f} \frac{\left(y_{s}+z_{s}-z_{r}\right)^{\tan \gamma_{o}-1}}{\left(z_{\text {surf }}-z_{r}\right)^{\tan \gamma_{o}}} \tan \gamma_{o} \frac{d y_{s}}{d t}$

(if $y_{s}+z_{s} \geq z_{r}$ )

where $\alpha_{s f}(-)$ is a scaling factor, which can be estimated from the surface runoff coefficient taking into account the average groundwater level. $y_{s}, z_{s}, z_{r}, z_{s u r f}$ and $\gamma_{o}$ are the geometric quantities of a REW defined in Fig. 2.

There are a number of geometric relationships supplementary to the balance equations, among those:

$\omega_{o}+\omega_{c}=1$

$y_{u} \omega_{c}+y_{s}=Z$

where $Z$ is the average soil depth of a REW. As a result,

$\frac{d \omega_{c}}{d t}=-\frac{d \omega_{o}}{d t}$

$\frac{d}{d t}\left(y_{u} \omega_{c}\right)=-\frac{d y_{s}}{d t}$

In Eq. (5), $e_{s a}$ is the sink (groundwater abstraction) or source (artificial recharge) term, which can be calculated by

$e_{s a}=\rho G A$

where $G\left(\mathrm{LT}^{-1}\right)$ is the abstraction or recharge rate imposed on the REW in question.

Substituting Eqs. (7), (8), (9), (10), (11), (12), (13), (16), (17), (18), (19), (20), (21), (27), (28) and (29) into Eqs. (2), (3), (4), (5) and (6), we obtain the full water balance equations for a REW.

$$
\begin{aligned}
& \frac{d y_{c}}{d t}=\underbrace{i}_{\text {rainfall }}-\underbrace{\min \left(i, i_{d c}\right)}_{\text {interception }}- \\
& \underbrace{\min \left[\left(i-i_{d c}\right), \frac{K_{s u}}{\Lambda_{u}}\left(\frac{1}{2} y_{u}+h_{c}\right)\right]}_{\text {infiltraion }}+\underbrace{\frac{y_{c}}{1-\omega_{o}} \frac{d \omega_{o}}{d t}}_{\text {area change }}
\end{aligned}
$$

$$
\frac{d y_{o}}{d t}=\underbrace{i}_{\text {rainfall }}-\underbrace{e_{p}}_{\text {evaporation }}+\underbrace{\frac{K_{s s}}{\Lambda_{s} \cos \gamma_{o}}\left(h_{s}-h_{o}\right)}_{\text {groundwater exfiltration }}
$$

$-\underbrace{\frac{2 y_{o} l_{r}}{A \omega_{o}} \frac{1}{n}\left(\sin \gamma_{o}\right)^{1 / 2}\left(y_{o}\right)^{2 / 3}}_{\text {overland flow to channel }}-\underbrace{\frac{y_{o}}{\omega_{o}} \frac{d \omega_{o}}{d t}}_{\text {area change }}$ 
Table 1. Flow processes, the flux terms and the closure relations.

\begin{tabular}{|c|c|c|}
\hline Processes & Flux terms & Closure relations \\
\hline Infiltration & $e_{c u}$ & $\begin{array}{l}\min \left[\left(i-i_{d c}\right), \frac{K_{s u}}{\Lambda_{u}}\left(\frac{1}{2} y_{u}+h_{c}\right)\right] \rho \mathrm{A} \omega_{u} \\
\text { (Darcy-type equation) }\end{array}$ \\
\hline $\begin{array}{l}\text { Percolation/ } \\
\text { Capillary rise }\end{array}$ & $e_{u s}$ & $\begin{array}{l}\alpha_{u s} \rho \omega_{c} A \frac{K_{u}}{y_{u}}\left[\left(\frac{1}{2}-\frac{\theta_{u}}{\varepsilon_{u}}\right) y_{u}+h_{c}\right] \\
\text { (Darcy-type equation) }\end{array}$ \\
\hline Overland flow & $e_{o r}$ & $\begin{array}{l}2 \rho y_{o} l_{r} \frac{1}{n}\left(\sin \gamma_{o}\right)^{1 / 2}\left(y_{o}\right)^{2 / 3} \\
\text { (Manning's equation) }\end{array}$ \\
\hline Exfiltration to surface & $e_{s o}$ & $\begin{array}{l}\frac{\rho K_{s s} \omega_{o} A}{\Lambda_{s} \cos \gamma_{o}}\left(h_{s}-h_{o}\right) \\
\text { (Darcy-type equation) }\end{array}$ \\
\hline \multirow[t]{2}{*}{ Channel flow } & $e_{\text {rin }} / e_{\text {rout }}$ & $\begin{array}{l}\rho \sum_{i} \frac{1}{2} m_{r i}\left(v_{r}+v_{r i}\right) \\
\rho \frac{1}{2} m_{r}\left(v_{r}+v_{r j}\right)\end{array}$ \\
\hline & & $\begin{array}{l}v_{r}=\sqrt{\frac{8 g}{P_{r} l_{r} \xi}\left[m_{r} l_{r} \sin \gamma_{r}+\sum_{i} \frac{1}{4} y_{r}\left(m_{r}+m_{r i}\right)-\frac{1}{4} y_{r}\left(m_{r}+m_{r j}\right)\right.} \\
\text { (simplified Saint-Venant Equation) }\end{array}$ \\
\hline Base flow & $e_{s r}$ & $\begin{array}{l}\frac{\rho K_{s r} l_{r} P_{r}}{\Lambda_{r}}\left(h_{r}-h_{s}\right) \\
\text { (Darcy-type equation) }\end{array}$ \\
\hline Inter-REW groundwater flow & $e_{s i}$ & $\begin{array}{l}\alpha_{s i} \rho\left(h_{s}-h_{s i}\right) \\
\text { (Darcy-type equation) }\end{array}$ \\
\hline
\end{tabular}

$$
\begin{aligned}
& \frac{d \theta_{u}}{d t}=\underbrace{\min \left[\frac{\left(i-i_{d c}\right)}{y_{u}}, \frac{K_{s u}}{y_{u} \Lambda_{u}}\left(\frac{1}{2} y_{u}+h_{c}\right)\right]}_{\text {infiltration }}- \\
& \underbrace{\min \left(1.0, \frac{2 \theta_{u}}{\varepsilon_{u}}\right) \frac{\left[e_{p}-\min \left(i, i_{d c}\right)\right]}{y_{u}}}_{\text {transpiration }} \\
& -\underbrace{\alpha_{u s} \frac{K_{u}}{y_{u}^{2}}\left[\left(\frac{1}{2}-\frac{\theta_{u}}{\varepsilon_{u}}\right) y_{u}+h_{c}\right]}_{\text {percolation/capillary rise }}+\underbrace{\frac{\theta_{u}}{y_{u} \omega_{u}} \frac{d y_{s}}{d t}}_{\text {water table change }}
\end{aligned}
$$

$$
\frac{d y_{s}}{d t}=\underbrace{\frac{\alpha_{u s} K_{u} \omega_{c}}{\varepsilon_{s} y_{u}}\left[\left(\frac{1}{2}-\frac{\theta_{u}}{\varepsilon_{u}}\right) y_{u}+h_{c}\right]}_{\text {percolation/capillary rise }}-
$$$$
\underbrace{\frac{K_{s s} \omega_{o}}{\varepsilon_{s} \Lambda_{s} \cos \gamma_{o}}\left(h_{s}-h_{o}\right)}-\underbrace{\frac{K_{s r} l_{r} P_{r}}{A \varepsilon_{s} \Lambda_{r}}\left(h_{s}-h_{r}\right)}
$$$$
\text { groundwater exfiltration } \underbrace{}_{\text {base flow }}
$$

$$
-\underbrace{\frac{\alpha_{s i}}{A \varepsilon_{s}}\left(h_{s}-h_{s i}\right)}-\underbrace{\frac{G}{\varepsilon_{s}}}
$$$$
\text { regional groundwater flow sink/source }
$$

$$
\begin{aligned}
\frac{d m}{d t}= & \underbrace{i w_{r}}_{\text {rainfall }}-\underbrace{e_{p} w_{r}}_{\text {evaporation }}+\underbrace{\frac{K_{s r} P_{r}}{\Lambda_{r}}\left(h_{s}-h_{r}\right)}_{\text {base flow }}+ \\
& \underbrace{2 y_{o} \frac{1}{n}\left(\sin \gamma_{o}\right)^{1 / 2}\left(y_{o}\right)^{2 / 3}}
\end{aligned}
$$

lateral flow from sat. overland flow area

$$
+\underbrace{\sum_{i} \frac{1}{2 l_{r}} m_{i}\left(v_{r}+v_{r i}\right)}_{\text {channel inflow }}-\underbrace{\frac{1}{2 l_{r}} m\left(v_{r}+v_{r j}\right)}_{\text {channel outflow }}
$$

These five equations, supplemented with geometric relations, form the mathematical core of the REWASH model code. For the solution of this system of equations, an adaptive-stepsize controlled Runge-Kutta algorithm presented by Press et al. (1992) has been adopted. This algorithm, using the Cash and Karp (1990) approach, limits the local truncation error at every time step to achieve a higher accuracy and robustness of the solution scheme.

\subsubsection{Treatment of sub-grid variability of soil properties within a REW}

Since Beven (1984) showed that there is decay in hydraulic conductivity with soil depth and Kirkby (1997) discussed the form of porosity decay, we have applied a division of the soil column to take into account the sub-grid variability of soil 

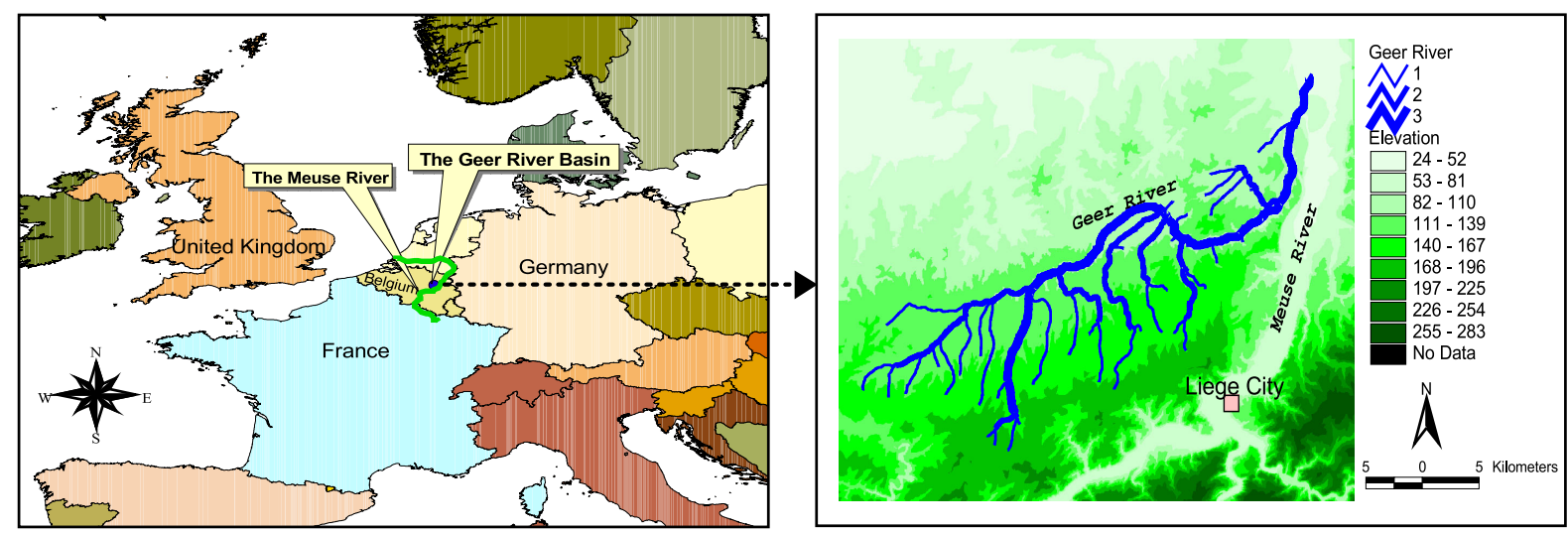

Fig. 3. Location of the Geer river basin and the Geer river network.

properties. In the real world, the variability of soil properties is one of the factors that induce quick subsurface storm flow. Within a REW, the soil column is divided into two layers. The average porosity and saturated hydraulic conductivity of the upper layer are larger than those of the lower layer. It should be pointed out that this division of the soil profile does not necessarily coincide with the boundary between the unsaturated and saturated zones as the consequence of varying water table depth. Therefore, the effective porosity of these two zones should be updated in time. Applying a depth-weighted averaging method, the effective porosity of both subsurface zones are given by:

$$
\begin{aligned}
& \left\{\begin{array}{c}
\varepsilon_{u}=\left[\varepsilon_{u}^{\prime} d_{u p}+\varepsilon_{s}^{\prime}\left(y_{u}-d_{u p}\right)\right] / y_{u}\left(\text { if } y_{u}>d_{u p}\right) \\
\varepsilon_{u}=\varepsilon_{u}^{\prime}\left(\text { if } y_{u} \leq d_{u p}\right)
\end{array}\right. \\
& \left\{\begin{array}{c}
\varepsilon_{s}=\left[\varepsilon_{u}^{\prime}\left(d_{u p}-y_{u}\right)+\varepsilon_{s}^{\prime}\left(z_{s u r f}-z_{r}-d_{u p}\right)\right] / \\
\left(z_{\text {surf }}-z_{r}-d_{u p}\right)\left(\text { if } y_{u}<d_{u p}\right) \\
\left.\varepsilon_{s}=\varepsilon_{s}^{\prime} \text { (if } y_{u} \geq d_{u p}\right)
\end{array}\right.
\end{aligned}
$$

where $\varepsilon_{u}^{\prime}(-)$ and $\varepsilon_{s}^{\prime}(-)$ are the soil porosity of the upper layer and the lower layer of the soil column, respectively; $d_{u p}(\mathrm{~L})$ is the depth of the upper soil layer. By this parameterisation, in combination with the field capacity threshold, which controls when percolation takes place, the time scales of the flow processes in the two subsurface domains can be better represented.

\section{Model application}

\subsection{Site description}

The Geer river basin has been selected for this study. The Geer river is a tributary of the Meuse River, located in Belgium (Fig. 3). The drainage area covers about $490 \mathrm{~km}^{2}$. The basin is characterised by a deep groundwater system, which is delimited at the southern end by a ridge separating it from the Meuse River. The substrata are made up by several layers of chalk stone with low permeability. The groundwater aquifer of the basin consists of Cretaceous chalks with a thickness ranging from a few meters in the south to about $100 \mathrm{~m}$ in the north. The aquifer is underlain by a layer of Smectite, which can be regarded as an impervious bottom boundary. The unsaturated zone above the aquifer can be up to $40 \mathrm{~m}$. The groundwater catchment does not correspond to the surface hydrological divide and extends beyond the catchment boundaries, thus water most likely flows across the northern topographical divide. Moreover, there is groundwater abstraction from wells and there are drainage galleries in the basin. Spatial data, a DEM with $30 \mathrm{~m} \times 30 \mathrm{~m}$ resolution, as well as four years (1 January 1993-31 December 1996) of daily rainfall, potential evaporation and discharges at the outlet are available.

\subsection{Model calibration and sensitivity analysis}

Model calibration is a procedure to adjust parameter values to achieve an optimal fit of model output to the corresponding measurements according to predefined objective function(s) and performance measure(s). It involves model performance evaluation, which is to analyse the closeness of model behaviour to the behaviour of the real world (Wagener, 2003). In General, objective function(s) and performance measure(s) are chosen, often subjectively, depending on the purpose of the model application and issues to be investigated. The approach used for calibration here is a combination of manual and automatic calibration strategy. NashSutcliffe efficiency $\left(R_{N S}^{2}\right.$, Nash and Sutcliffe, 1970) and the percentage bias $\left(\delta_{B}\right)$ are used for evaluating model performance. Since the goal of this work is not to pursue a best model (or to find a best parameter set) but to show how a REW approach based model can be applied to in a real world catchment, we chose a level of 0.6 for $R_{N S}^{2}$ as the threshold to discriminate a behavioural and non-behavioural model. 


\subsubsection{Parameter assignment and manual calibration}

The river basin has been discretised into a finite number of sub-watersheds, i.e. REWs, and the river network linking each REW has been generated using the modified version of TARDEM (Tarboton, 1997). A second order threshold on the Strahler river order system (Strahler, 1957) resulted in 73 REWs (see Fig. 4). The parameters of the model consist of the interception threshold, surface roughness and channel friction factor, soil properties and hydraulic characteristics. All these parameters are effective values at REW-scale. Owing to the lack of spatially distributed information of these parameters as well as some of the geometric properties, such as the average total soil depth, the depth of the upper soil layer, and the river bed transition layer depth, we assume that they are uniformly distributed over the entire river basin. The initial state of the river basin is also assumed spatially uniform. As a result, the model functions as a lumped model. On the other hand, it decreases the model parameters to a more manageable number and reduces drastically the calibration task, making a quick evaluation of the model at the early development stage possible. For the derivation of initial estimates of soil parameters, we made a realistic guess based on published values (e.g. Troch et al., 1993). Rainfall and potential evaporation (based on Penman-Monteith equation) data, measured at Bierset gauging station (Fig. 4) from 1 January 1993 to 31 December 1994 were used in simulation runs for calibration. Discharge data, measured at the outlet of the catchment in the same period were used for calibration. The remaining two years of data were used for verification run. No data measured at interior flow gauges was available. It has been observed that the 4-year of data available for this study cover both wet and dry periods, high and low flows. Further, no drastic changes in climate and land use, which could lead to changes of catchment rainfall runoff relations, have been documented. Therefore, the quantity and quality of the data applied in this case is justified.

Knowing that water flows across the northern divide of the river basin, we imposed a flux boundary condition for those REWs bordering the northern divide (REW12, REW13, REW25, REW26, REW27, REW52, REW69 and REW73). With respect to groundwater abstractions, sink terms have been synthesised as monthly time series on the basis of available data and introduced to the saturated zone mass balance equation for each REW. In addition, groundwater flow interactions between neighbouring REWs are considered explicitly computed with Eq. (18).

It has appeared that the model needs around half a year of run time for model initialisation (warming-up). We therefore run the model using the time series for one year to reach a quasi dynamic equilibrium state. Subsequently we used this state as the initial state for model calibration so that the warming-up effect can be reduced to a negligible level. By applying a trial-and-error method, expert knowledge has been used to identify parameter values. During manual cali-

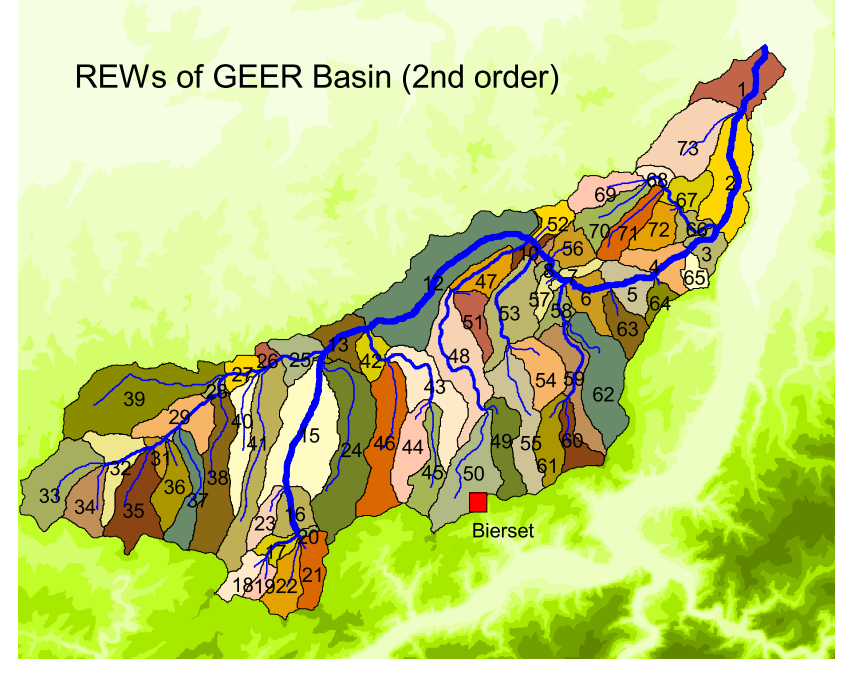

Fig. 4. Discretisation of the Geer river basin and the resultant REWs.

bration, the most sensitive parameters have been recognised and physically meaningful ranges for those parameters determined. In calibration, two constants, namely the scaling factors, $\alpha_{u s}$ and $\alpha_{s f}$ in Eq. (13) and Eq. (23), respectively, were not subject to adjustment. In Eq. (13), $\alpha_{u s}$ is the scaling factor resulted from linearisation of the dependent function of the mass exchange between the unsaturated domain and the saturated domain (Reggiani et al., 2000). In this study, similar to Reggiani et al. (2000), we used the unsaturated soil porosity for $\alpha_{u s}$, implying that the flow (recharge/capillary rise flux) is conducting only through soil pores. As described in Zhang et al. (2005a), $\omega_{o}$ being a function of groundwater level and surface slope, acts, in fact, as a surface runoff coefficient. With regard to $\alpha_{s f}$, we observe that in the right hand side of from Eq. (23), the entire term within the brackets and its exponent vary between 0 and 1 . Therefore, $\alpha_{s f}$ should not be larger than the catchment runoff coefficient. For a first estimation of $\alpha_{s f}$, the runoff coefficient, and preferably, the surface runoff coefficient can be assigned.

During calibration, priority was given to fitting low flows. While visually inspecting the goodness of fit (comparison of the simulated hydrograph against the observed), objective measures such as the Nash-Sutcliffe efficiency $\left(R_{N S}^{2}\right.$, Nash and Sutcliffe, 1970), the percentage bias $\left(\delta_{B}\right)$ have been used to evaluate the fit. The definition of $R_{N S}^{2}$ and $\delta_{B}$ are given as follows:

$R_{N S}^{2}=1.0-\frac{\sum_{i=1}^{n}\left(Q_{s i}-Q_{o i}\right)^{2}}{\sum_{i=1}^{n}\left(Q_{o i}-\bar{Q}_{o}\right)^{2}}$ 
$\delta_{B}=\left|\frac{\sum_{i=1}^{n}\left(Q_{s i}-Q_{o i}\right)}{\sum_{i=1}^{n} Q_{o i}}\right| \times 100 \%$

where $Q_{s i}, Q_{o i}$ and $\bar{Q}_{o}$ are the simulated discharge, the observed discharge at the time step $i$ and the mean of the observed discharge, respectively. $\delta_{B}$ represents the difference of the total volume between the simulated and observed time series. The bias is an important measure to evaluate simulation of continuous models.

To give more information on how the model simulates the stream flow in different flow ranges, average relative errors $\left(\delta_{p}\right)$ were calculated. $\delta_{p}$ is expressed as

$\delta_{p}=\frac{1}{n} \sum_{i=1}^{n}\left(\frac{\left|Q_{s i}-Q_{o i}\right|}{Q_{o i}} \times 100 \%\right)$

where $Q_{s i}$ and $Q_{o i}$ are the same as in previous equations.

\subsubsection{Sensitivity analysis}

Sensitivity analysis (SA) is a useful tool to assess the effect of parameter perturbations on model output. Many techniques for SA are available and they can be categorised into three groups (see e.g. Saltelli, 2000): 1) factor screening, 2) local SA, and 3) global SA (often applied as regional sensitivity analysis, RSA, in rainfall-runoff applications). The Fourier amplitude sensitivity test (FAST) and Monte Carlo simulation based methods (e.g. Hornberger and Spear, 1981; Beven and Binly, 1992; Freer et al., 1996) are among the popular RSA approaches, which found their applications mostly for conceptual rainfall-runoff models. Apparently, local SA approaches don't take into account the effect of parameter interactions. RSA approaches implicitly account for the parameter interaction effect and can explore a higher dimensional parameter space. However, few reports in rainfallrunoff modelling have explicitly discussed the effect of parameter interactions on the parameter indentifiability. In fact, as Bastidas et al. (1999) and Wagener et al. (2004) pointed out, most SA approaches are weak in dealing with the issue of parameter interdependency. On the other hand, due to the "curse of dimensionality" (Brun et al., 2001) and prohibitively high computational demand, RSA approaches are not widely applied yet to large complex models. Instead, local approaches are often used (e.g. Senarath et al., 2000; Newham et al., 2003).

We used the one-at-a-time perturbation approach to preliminarily investigate the effect of parameter variation on the model output that assists in gaining insight into model behaviour, although sensitivity analysis is not the main goal of this work. This approach can be regarded as an expansion of factor screening that is helpful to filter out most important factors affecting model response. In this study, starting with the manual calibration, each parameter has been varied by $+50 \%$ and $-50 \%$ while the other parameters were maintained unchanged. Having gained a knowledge of which parameters are most sensitive in manual calibration, we chose six parameters $\left(i_{d c}, K_{s u}, K_{s s}, \varepsilon_{s}^{\prime}, \varepsilon_{u}^{\prime}, \lambda\right)$ to further evaluate model sensitivity. Using the relative change in runoff volume $\left(\delta_{V}\right)$ and the relative change in Nash-Sutcliffe efficiency $\left(\delta_{N S}\right)$ as indices, the effect of each parameter change on the runoff-producing events during the period from $1 \mathrm{Jan}$ uary 1993 to 31 December 1993 has been analysed. $\delta_{V}$ and $\delta_{N S}$ are defined as follows:

$\delta_{V}=\left|\frac{\sum_{i=1}^{n}\left(Q_{i+}-Q_{i-}\right)}{\sum_{i=1}^{n} Q_{i m}}\right| \times 100 \%$

where $Q_{i+}, Q_{i-}$ and $Q_{i m}$ refer to the discharges at the time step $i$ with the parameter value varied by $+50 \%,-50 \%$ and the manually calibrated parameter value, respectively. The larger the $\delta_{V}$, the more sensitive the model is to the parameter under study.

$\delta_{N S}=\left|\frac{R_{N S+}^{2}-R_{N S-}^{2}}{R_{N S m}^{2}}\right| \times 100 \%$

where $R_{N S+}^{2}, R_{N S-}^{2}$ and $R_{N S m}^{2}$ are the Nash-Sutcliffe efficiency values with the parameter value varied by $+50 \%$, $-50 \%$ and the manually calibrated parameter value, respectively. Same as $\delta_{V}$, the larger the $\delta_{N S}$, the more sensitive the model to the parameter under study.

\subsubsection{Automated parameter optimisation}

A hybrid approach combining manual and automated calibration methods is increasingly recognised as a more effective way of parameter optimisation (Boyle et al., 2000). Boyle et al. (2000) first carried out automatic calibration using the MOCOM-UA algorithm to obtain the Pareto solution space and then selected one or more acceptable parameter sets within the Pareto space through manual calibration. Obviously this calibration strategy has the advantage that a group of good parameter sets can be efficiently filtered out by the automatic step. In our case, however, the model is newly built and further development is still underway. Thus, an open-eyes manual calibration is a desirable way of gaining knowledge of model behaviour. Moreover, the model is physically based so that parameters should be calibrated within physically reasonable ranges, which have to be defined before an automatic calibration step. Therefore, we carried out manual calibration in the first step followed by automatic calibration.

Following the trial-and-error procedure, we carried out an automatic calibration procedure to enhance the accuracy of the model optimisation. During the manual calibration, physically reasonable ranges of parameter values have been delineated. These ranges were then prescribed in the automatic 
Table 2. The accepted best parameter values for the calibration period and the model performance.

\begin{tabular}{llllllllll}
\hline Parameters & $\begin{array}{l}i_{d c} \\
(\mathrm{~mm} / \mathrm{d})\end{array}$ & $\begin{array}{l}n \\
\left(\mathrm{~s} / \mathrm{m}^{1 / 3}\right)\end{array}$ & $\begin{array}{l}K_{s s} \\
(\mathrm{~m} / \mathrm{d})\end{array}$ & $\begin{array}{l}K_{s u} \\
(\mathrm{~m} / \mathrm{d})\end{array}$ & $\begin{array}{l}K_{S r} \\
(\mathrm{~m} / \mathrm{d})\end{array}$ & $\begin{array}{l}\varepsilon_{s}^{\prime} \\
(-)\end{array}$ & $\begin{array}{l}\varepsilon_{u}^{\prime} \\
(-)\end{array}$ & $\begin{array}{l}\lambda \\
(-)\end{array}$ & $\begin{array}{l}\theta_{f} \\
(-)\end{array}$ \\
\hline Value & 1.36 & 0.020 & 0.0097 & 0.0213 & 2.64 & 0.148 & 0.43 & 4.43 & 0.08 \\
$R_{N S}^{2}$ & 0.71 & & & & & & & & \\
$\delta_{B}$ & $0.76 \%$ & & & & & & & & \\
\hline
\end{tabular}

calibration procedure for the fine adjustment of parameter values. In this work, the optimisation tool GLOBE (Solomatine, 1995, 1998) has been coupled to REWASH. GLOBE is a global optimisation tool consisting of a number of search algorithms: controlled random search (CRS2, CRS4); genetic algorithm (GA); adaptive cluster covering (ACCO), and with local search (ACCOL); multistart methods (e.g. Msimplex) etc. We choose the M-simplex algorithm for our study, though Sorooshian et al. (1993) discussed that the Msimplex algorithm is not as efficient and effective as the shuffled complex evolution algorithm. In our modelling exercises, we also have tried different algorithms (GA, ACCOL). However, the accuracy gained was marginal and the computational efficiency was found lower than that with the Msimplex. Figure 5 shows the loop of the automated calibration procedure. P_obj and P_update are the two programmes linking REWASH to GLOBE. These programmes are driven by GLOBE in each evaluation loop, in which P_update takes the values of the parameter set generated from GLOBE and updates the input files for the REWASH, and P_obj provides the error value calculated with a specified objective function (i.e. $R_{N S}^{2}$ for this work) to GLOBE.

\subsection{Model verification}

Model verification has been performed to test whether the model, using the same parameter set obtained by optimisation, but with independent data sets, can produce outputs with reasonable accuracy. A classical method for model verification, the split-sample test (Klemes, 1986) has been applied since there is no indication that there has been an abrupt change of the basin characteristics and conditions over the time domain of the investigation. The data set from 1 January 1995 to 31 December 1996 has been used for the verification test. To examine whether the model can perform in a consistent manner in terms of simulating the real system within the range of accuracy, a model validity test has been conducted by reversing calibration and verification periods. In this analysis, the data set of the period from 1 January 1995 to 31 December 1996 is used for calibration while the other part of the data set is used for verification.

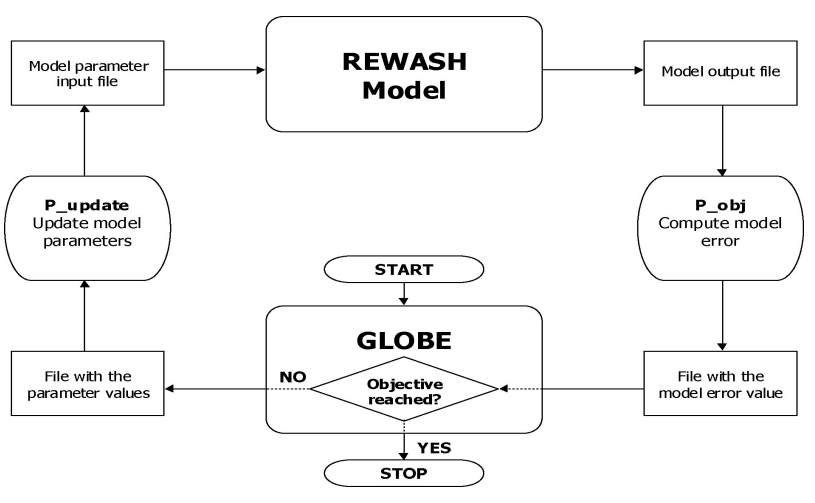

Fig. 5. Flow chart of the automatic calibration procedure (after Solomatine, 1998).

\section{Results and discussion}

\subsection{Model calibration}

After manual and automatic calibration with a limited number of parameters $\left(i_{d c}, K_{s u}, K_{s s}, \varepsilon_{s}^{\prime}, \varepsilon_{u}^{\prime}, \lambda\right)$, the NashSutcliffe efficiency of the model reached 0.71 , while the volume error represented by $\delta_{B}$ was only $0.76 \%$. Table 2 lists the accepted best parameter values and the model performance. The values of the saturated hydraulic conductivity of the unsaturated zone and the soil porosity of the upper soil layer are more than twice as high as those of the saturated zone and of the lower soil layer, respectively. The $\lambda$ value indicates that the soil type is silty loam, which agrees with other soil property indicators, such as $K_{s u}$ and $\varepsilon_{u}^{\prime}$.

Figure 6 shows the comparison of the simulated and observed hydrographs (Fig. 6b), and the accumulated discharges for the simulated and observed data at the outlet of the Geer river basin (Fig. 6c). Clearly, the pattern of the watershed response to the atmospheric forcing is well captured. The base flow is quite accurately reproduced in the calibration period except for the beginning 3 months, mostly due to the model warming up effect. Most peaks are simulated with reasonable accuracy although some peaks in the period from 340 days to 480 days (Fig. 6 b) are underestimated. We also observed that three peaks in the period from 560 days to 580 days are overestimated compared with the measured 
Table 3. Average relative simulation errors in different flow ranges.

\begin{tabular}{cccc}
\hline & \multicolumn{3}{c}{ Averaged relative errors $\delta_{p}(\%)$} \\
\cline { 2 - 4 } $\begin{array}{c}\text { Flow }(Q) \text { ranges } \\
\left(\mathrm{m}^{3} / \mathrm{s}\right)\end{array}$ & $\begin{array}{c}\text { Calibration results } \\
(1993-1994)\end{array}$ & $\begin{array}{c}\text { Calibration results } \\
\text { without interception } \\
(1993-1994)\end{array}$ & $\begin{array}{c}\text { Verification results } \\
(1995-1996)\end{array}$ \\
\hline $\mathrm{Q} \leq 1.0$ & 9.7 & 6.5 & - \\
$1.0<Q \leq 2.0$ & 15.0 & 17.7 & 19.8 \\
$2.0<Q \leq 6.0$ & 19.5 & 24.9 & 25.4 \\
$6.0<Q \leq 8.0$ & 38.6 & 41.9 & 15.9 \\
$>8.0$ & 22.2 & 27.0 & 36.9 \\
\hline
\end{tabular}

data. However, we argue that these under- and overestimation for the peaks are not entirely due to the modelling errors but also as result of data errors and the neglecting spatial distribution of rainfall. If we examine the rainfall data (Fig. 6a) in the period between day 560 and day 580, there are three rainfall events with relatively high rainfall intensity ranging from 11.8 to $24.4 \mathrm{~mm} / \mathrm{d}$. These events should have produced higher stream flows than observed. The inconsistency between the rainfall observations and the discharge measurements is most likely due to the fact that only one rainfall station was used for the simulation. The flow duration curves (Fig. 7) for the simulated and observed discharges show that low flows are better simulated than middleranged flows when comparing to the measured data. This is confirmed by Table 3 . For low flows $\left(Q \leq 1.0 \mathrm{~m}^{3} / \mathrm{s}\right.$, and $\left.1.0 \mathrm{~m}^{3} / \mathrm{s}<Q \leq 2.0 \mathrm{~m}^{3} / \mathrm{s}\right)$, the averaged relative errors $\left(\delta_{p}\right)$ are $9.7 \%$ and $15.0 \%$, respectively. They are significantly smaller than those for flows in the ranges of $2.0-6.0 \mathrm{~m}^{3} / \mathrm{s}$ and 6.0 $8.0 \mathrm{~m}^{3} / \mathrm{s}$, which are $19.5 \%$ and $38.6 \%$, respectively. Yet we realise that the model involves parameter uncertainties since there are no catchment-scale parameters ever measured or detailed data on state variables other than discharge to confirm the calibrated model parameters. This remains a challenge for ongoing and future research.

\subsection{Model sensitivity to parameters}

A set of computer runs has been implemented to test model sensitivity to parameters listed in Table 4 . The analysis primarily focused on subsurface parameters. Table 4 shows that runoff simulations are most sensitive to the soil poredisconnectedness $\lambda$ and the soil porosity of the lower soil layer $\varepsilon_{s}^{\prime} . \lambda$ mostly affects the runoff volume while $\varepsilon_{s}^{\prime}$ has the strongest effect on the Nash-Sutcliffe efficiency. This can be explained if we recall the equations described in Sect. 2 . From Eqs. (10), (14), (15) and (32), we see that $\lambda$ is the one that determines the unsaturated hydraulic conductivity and the unsaturated zone hydraulic potential, and hence the infiltration capacity and the percolation flux. From Eq. (33), one can observe that $\varepsilon_{s}^{\prime}$ dictates the subsurface storage and inter-
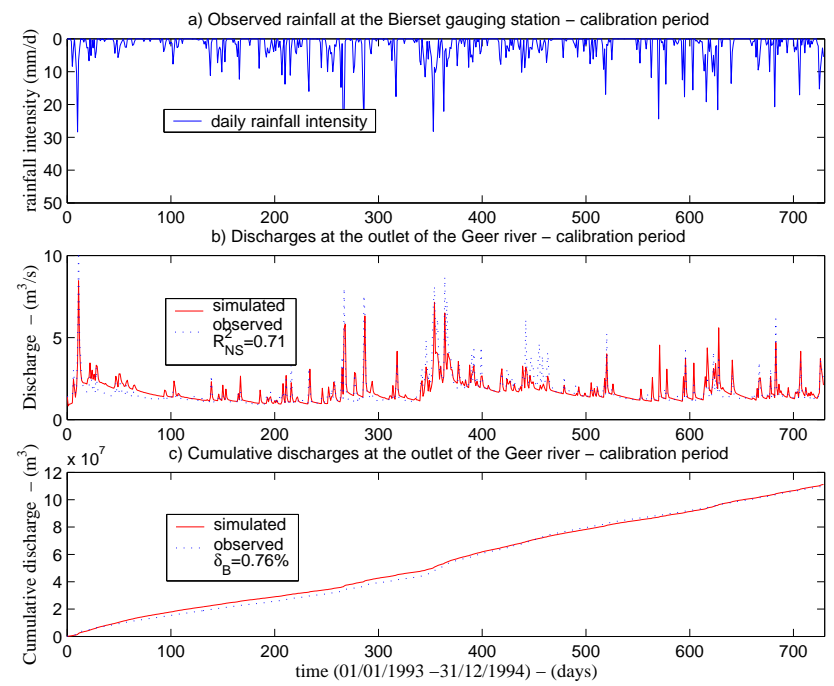

Fig. 6. Comparison of the simulated and the observed hydrograph and cumulative discharge volume at the basin outlet for the calibration period (1 January 1993-31 December 1994): (a) the rainfall, (b) the observed and simulated discharge, (c) the accumulated observed and simulated runoff.

actions between surface and subsurface flows. Meanwhile, these equations also explain the significance of $K_{s s}$ and $\varepsilon_{u}^{\prime}$ in model performance. The test results already suggested a remarkable effect of the interception threshold $i_{d c}$ on runoff generation although it's sensitivity is smaller than the subsurface parameters. The effect of $i_{d c}$ is discussed in more details in the following section.

\subsection{Effect of interception}

Applying the same forcing input, identical initial and boundary conditions, and the same parameters tuned in the model including interception (Fig. 6), the model excluding interception has been re-calibrated automatically. Figure 8 shows the comparison of the simulated hydrograph and the observed. Apparently, the model without interception performed much 


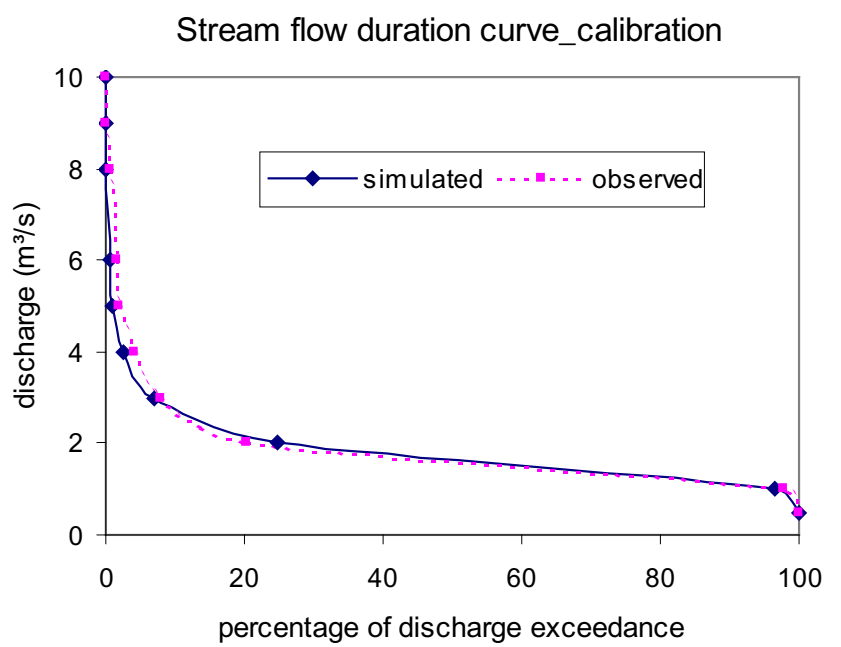

Fig. 7. Flow duration curves for the model calibration results and the observed data.

Table 4. Sensitivity of the model output to parameters.

\begin{tabular}{ccc}
\hline Parameters & $\delta_{V}(\%)$ & $\delta_{N S}(\%)$ \\
\hline$\lambda(-)$ & 190 & 1177 \\
$\varepsilon_{s}^{\prime}(-)$ & 109 & 1729 \\
$K_{s S}(\mathrm{~m} / \mathrm{d})$ & 81 & 45 \\
$\varepsilon_{u}^{\prime}(-)$ & 77 & 89 \\
$K_{s u}(\mathrm{~m} / \mathrm{d})$ & 10 & 6 \\
$i_{d c}(\mathrm{~mm} / \mathrm{d})$ & 10 & 5 \\
\hline
\end{tabular}

worse than the one with interception: $R_{N S}^{2}$ is $14 \%$ lower, and $\delta_{B}$ is $187 \%$ larger. Figure 9 shows the flow duration curves for the simulation outputs of both the models with and without interception, as well as for the observed flow records. Together with analysing the averaged relative error $\delta_{p}$ presented in Table 3, we can find that the model without interception does not cover the full range of the low flows, suggesting erroneous simulation of the water balance. This is because more water, which would have been intercepted, is adding to the subsurface stores, participating in the surface and subsurface flux exchanges, and subsequently contributes to stream flow. Especially during the smaller rainfall events, the part of the rainfall flux that would have been intercepted leads to a higher antecedent soil moisture state, which either initiates a quicker surface runoff or gives rise to higher stream flow during the low flow regime. In the simulation without interception, we see that low flows are higher than observed, e.g. in the period of the last 120 days (Fig. 8a). However, as the model tries to maintain overall performance in terms of total volume, the simulated flow mass curve enters into a more or less constant slope, which does not follow the bending of the observed flow mass curve after 360 days (Fig. 8b). In
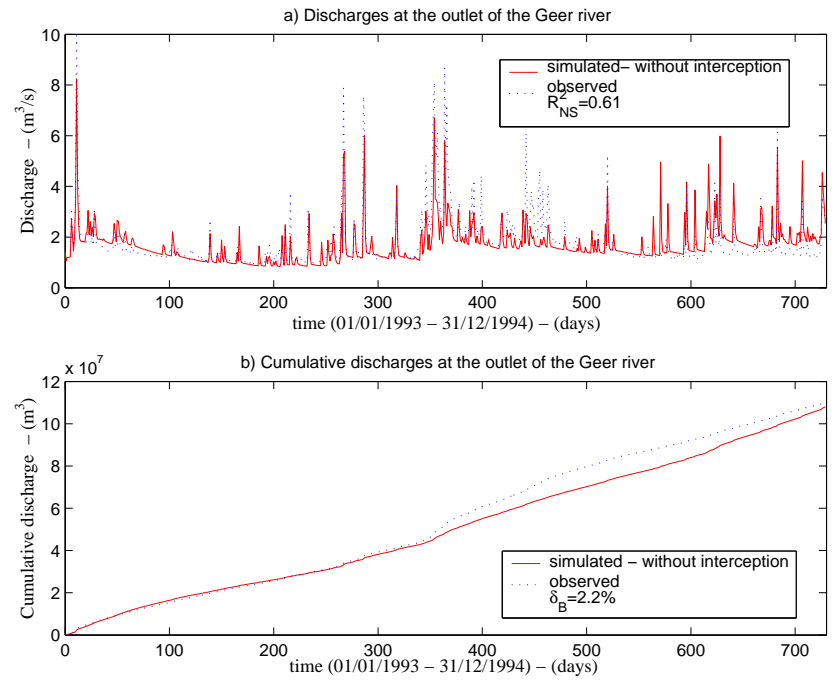

Fig. 8. Simulated discharge using the model without interception after optimisation (1 January 1993-31 December 1994): (a) observed and simulated discharge, (b) accumulated observed and simulated runoff.

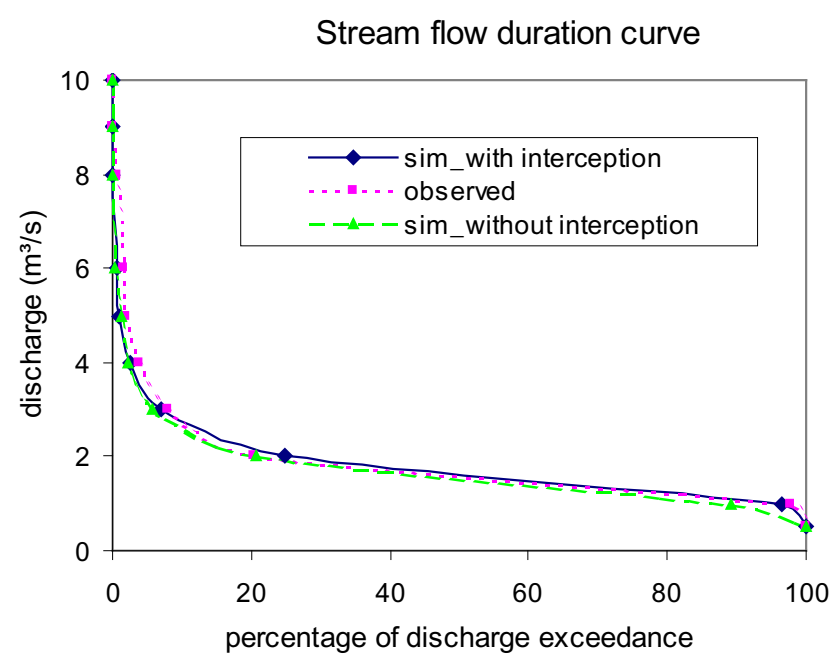

Fig. 9. Flow duration curves for the model calibration results (with interception and without interception) and the observed data.

Fig. 10, one can notice that without interception, the soil saturation is steadily increasing over time (dotted lines) for each of the REWs presented. However, one would expect that for a multiple-year simulation, the soil moisture state would preserve an equilibrium state while varying seasonally.

\subsection{Model verification}

The approach suggested by Klemes (1986) has been adopted to verify the model. A reversed calibration/verification test was also carried out. From Fig. 11, we can see that the model is able to reproduce most peaks except the one on day 525 . 

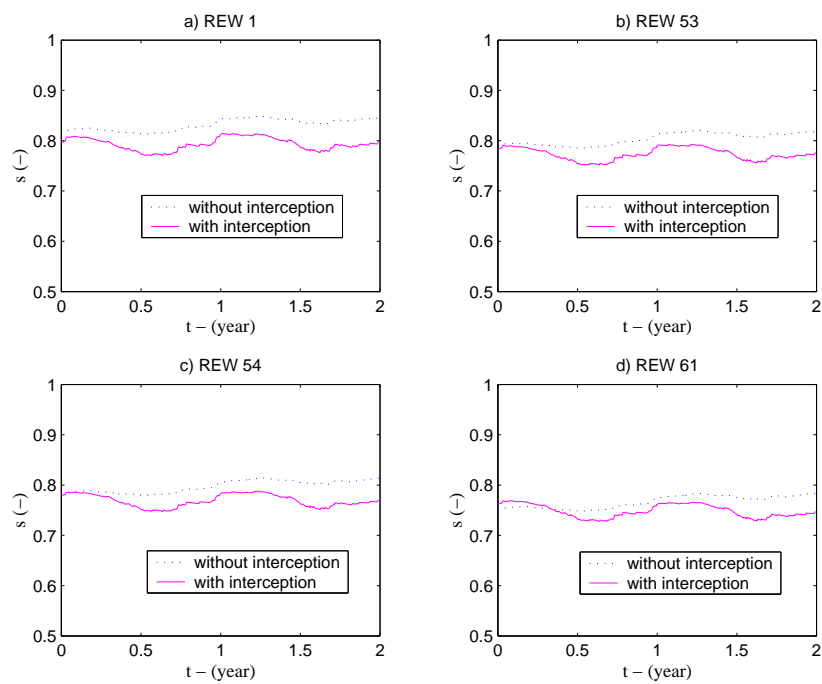

Fig. 10. Comparison of the hill-slope soil moisture dynamics simulated with and without interception process in the model. REW 53, REW54 and REW 61 compose a hill-slope of the catchment in the southern side of the Geer river.

Table 5. Model performance in the split-sample test runs.

\begin{tabular}{lcc}
\hline test & $\delta_{B}(\%)$ & $R_{N S}^{2}$ \\
\hline calibration (1993-1994) & 0.76 & 0.71 \\
verification (1995-1996) & 4.79 & 0.61 \\
reversed calibration (1995-1996) & 4.14 & 0.65 \\
reversed verification (1993-1994) & 3.82 & 0.68 \\
\hline
\end{tabular}

The observed discharge on this day is $9 \mathrm{~m}^{3} / \mathrm{s}$ and the rainfall causing this peak is $28 \mathrm{~mm} / \mathrm{d}$. Scanning all rainfall events and peak responses in the catchment in the period of 1993 1996, this data point is an exception lying outside the general rainfall runoff relation of the catchment. It is likely due to either a measurement error or the inadequate density of the rainfall observation network. As a result, it is not used for model performance analysis. In this verification run, low flows in most of the time are underestimated, which can be confirmed from the flow duration curve (Fig. 12). Actually, from Fig. 11b, we can find that the observed flow data exhibit more or less constant base flows and show no remarkable depleting trend in the dry period over the time from 1995 to 1996. This appearance is also shown in Fig. 12 in which there is an abrupt change of the probability distribution for the observed discharges from $2.0 \mathrm{~m}^{3} / \mathrm{s}$ to $1.0 \mathrm{~m}^{3} / \mathrm{s}$.

Table 5 reports the summary of the model performance in each of the calibration/verification runs. Figures 13 and 14 present the reversed calibration/verification tests. All these results demonstrate that the model, giving a similar volume error and Nash-Sutcliffe efficiency in each of the simulations, performs in a very consistent manner.
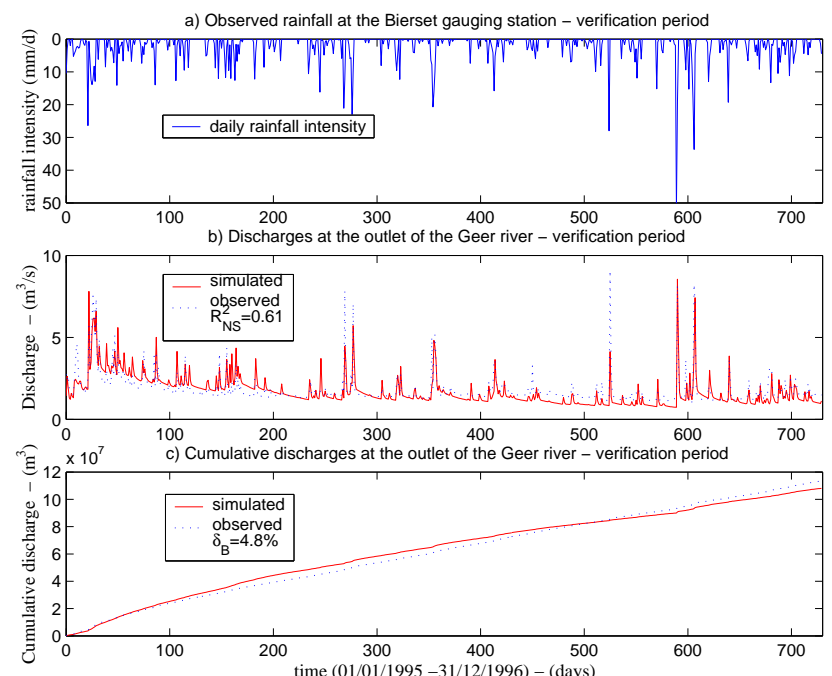

Fig. 11. Model verification results: (a) observed daily rainfall intensity at the Bierset station; (b) comparison of the simulated and observed daily discharge at the outlet of the Geer river basin; (c) comparison of the simulated and observed runoff volume (1 January 1995-31 December 1996).

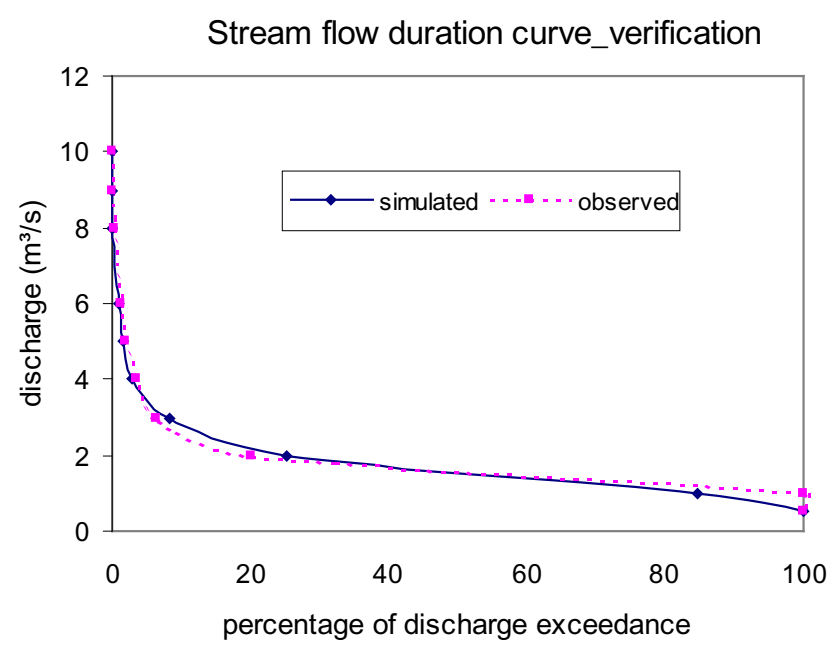

Fig. 12. Flow duration curves for the model verification results and the observed data.

\section{Summary and conclusions}

This paper has presented a comprehensive and convincing application of the REW-based spatially-distributed model to an actual meso-scale basin, with considerable spatial heterogeneity and between-REW interactions. The model has been improved by the addition of the interception process, improved transpiration scheme and improved saturation-excess flow area formulation. At the watershed-scale, surface and subsurface interaction, climate feedback, hill-slope and channel network have been fully coupled, based on physical 

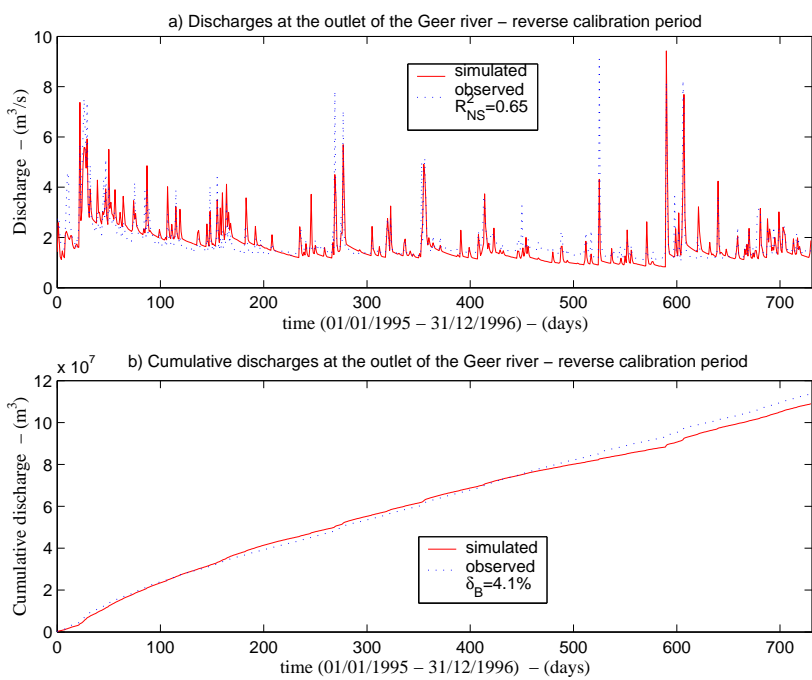

Fig. 13. Calibration results by reversing the calibration/verification periods (1 January 1995-31 December 1996): (a) observed and simulated discharge, (b) accumulated observed and simulated runoff.

principles. To enhance the model's numerical efficiency and stability, the momentum balance equations have been simplified by ignoring inertia terms, leading to algebraic forms of exchange fluxes. The mass balance equations have been converted into univariate derivative form so that a single variable is computed to represent the state of each flow domain at each time step. An adaptive-step-size controlled Runge-Kutta integration algorithm has been applied to solve the coupled system of equations, ensuring model stability while maintaining accuracy. The model has been coupled to the GLOBE optimization tool for automatic calibration.

The model has been applied to the Geer river basin, which lies in a temperate humid climate region. This basin has a complex subsurface where cross-boundary interactions and groundwater flows are essential features. It is further complicated by human interference through pumping and artificial underground drainage, giving rise to a great deal of difficulty in modelling its hydrological response. Model calibration was carried out using a combined manual and automatic method. The sample-split test resulted in a similar accuracy, suggesting that the model performs in a consistent manner in the study area. Judging by the Nash-Sutcliffe efficiency and volume percentage bias, it can be concluded that the simulated stream flows are reasonably accurate.

The introduction of interception in the model, in spite of the simplicity of the approach, showed that it improved the soil moisture accounting, resulting in a better stream flow simulation. Subject to the research objective, a more sophisticated module for interception, taking into account the effect of temporal and spatial variation due to vegetation type and their seasonal changes can be further investigated in the future.
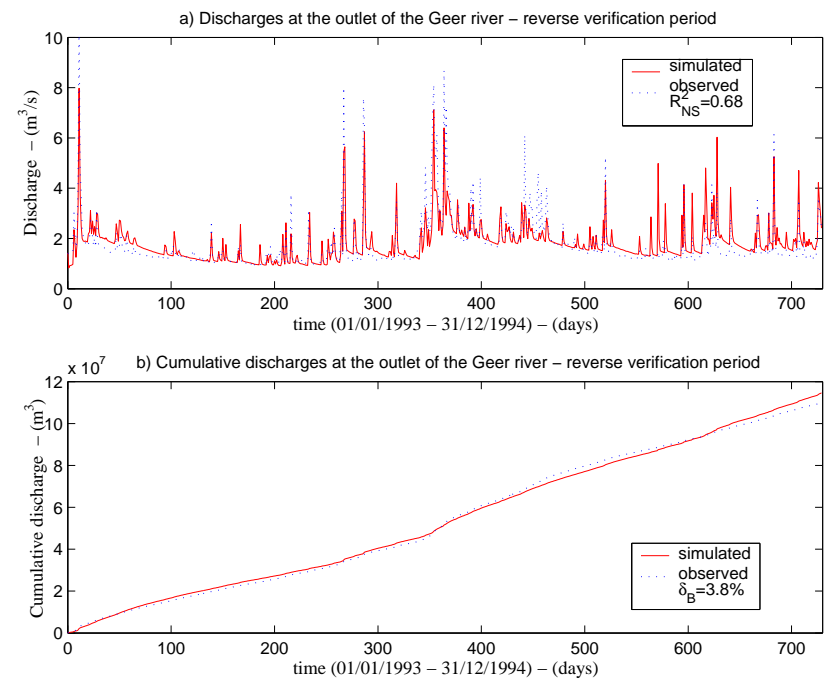

Fig. 14. Verification results by reversing the calibration/verification periods (1 January 1994-31 December 1995): (a) observed and simulated discharge, (b) accumulated observed and simulated runoff.

It is observed that deriving closure relations for mass exchange terms in the balance equations is the key to a successful application of the REW approach. In general, closure relations can be deducted from theoretical analysis, numerical experiments, field experiments, physical reasoning on intuitive grounds, and a combination of any of the abovementioned methods (e.g. Lee et al., 2005; Zehe et al., 2005). Taking the advantage of the REW approach for its flexibility, one can opt for an appropriate approach for the derivation of closure relations on a case-by-case basis, putting emphasis on those closure relations that are most relevant for the dominant processes in the catchment under study.

This paper demonstrates that the model, REWASH, presented here is capable of capturing watershed responses and simulating rainfall-runoff behaviour. Although there is still substantial work to be done before the model can be routinely applied in catchments with different physio-geographic and climatic settings, REWASH provides a general framework as an alternative for physically based distributed modelling approaches. One can tune this model or modify any functional relation to suite the characteristics of a specific study site.

\section{Appendix: Nomenclature}

Dimensions: $L=$ length; $T=$ time; $M=$ mass.

A

$d_{u p}$

$e_{p}$

$e_{\text {ctop }}, e_{\text {otop }}$,

$e_{\text {rtop }}$ horizontally projected surface area of a REW $\left(\mathrm{L}^{2}\right)$. depth of the upper soil layer (L). potential evaporation $\left(\mathrm{LT}^{-1}\right)$. rainfall flux to Czone, to Ozone and to River $\left(\mathrm{L}^{3} \mathrm{~T}^{-1}\right)$. 


\begin{tabular}{|c|c|c|}
\hline \multirow[t]{2}{*}{$e_{c a}, e_{c u}, e_{c o}$} & interception flux from Czone, infiltration & $y_{r}$ \\
\hline & flux to Uzone, flux between Czone and & $y_{s}, y_{u}$ \\
\hline \multirow{3}{*}{$\begin{array}{l}e_{o a}, e_{o s}, e_{o r}, \\
e_{o c}\end{array}$} & $\begin{array}{l}\text { Ozone }\left(\mathrm{L}^{3} \mathrm{~T}^{-1}\right) \text {. } \\
\text { evaporation flux from Ozone, flux be- }\end{array}$ & $z_{r}, z_{s}, z_{s u r f}$ \\
\hline & tween Ozone and Szone, flux between & $Z$ \\
\hline & $\begin{array}{l}\text { Ozone and River, flux between Ozone } \\
\text { and Czone }\left(\mathrm{L}^{3} \mathrm{~T}^{-1}\right) \text {. }\end{array}$ & $\alpha_{s f}$ \\
\hline \multirow[t]{2}{*}{$e_{u a}, e_{u c}, e_{u s}$} & $\begin{array}{l}\text { transpiration fux in Uzone, infiltration } \\
\text { flux from Czone, percolation flux to }\end{array}$ & $\alpha_{s i}$ \\
\hline & Szone $\left(\mathrm{L}^{3} \mathrm{~T}^{-1}\right)$ & $\alpha_{u s}$ \\
\hline \multicolumn{3}{|l|}{$e_{s u}, e_{s o}$} \\
\hline \multirow{2}{*}{$e_{s r}, e_{s i}, e_{s a}$} & flux between Szone and River, flux ex- & $\delta_{B}$ \\
\hline & $\begin{array}{l}\text { change between the neighbouring REWs, } \\
\text { groundwater abstraction }\left(\mathrm{L}^{3} \mathrm{~T}^{-1}\right) \text {. }\end{array}$ & $\delta_{N S}$ \\
\hline \multirow[t]{3}{*}{$e_{\text {ra }}, e_{\text {rin }}, e_{\text {rout }}$} & evaporation from River, flux from up- & $\delta_{V}$ \\
\hline & stream River, flux to the downstream & $\delta_{p}$ \\
\hline & River $\left(\mathrm{L}^{3} \mathrm{~T}^{-1}\right)$ & $\varepsilon_{u}^{\prime}, \varepsilon_{s}^{\prime}$ \\
\hline$e_{r s}, e_{r o}$ & the counterpart of $e_{s r}$ and $e_{o r}$. & \\
\hline$f$ & infiltration capacity $\left(\mathrm{L}^{3} \mathrm{~T}^{-1}\right)$. & $\varepsilon_{u}, \varepsilon_{s}$ \\
\hline$g$ & gravitational acceleration $\left(\mathrm{LT}^{-2}\right)$. & \\
\hline \multirow[t]{2}{*}{$G$} & groundwater abstraction or recharge rate & $\phi$ \\
\hline & $\left(\mathrm{L}^{3} \mathrm{~T}^{-1}\right)$ & $\gamma_{o}$ \\
\hline$h_{c}$ & capillary pressure head $(\mathrm{L})$. & \\
\hline$h_{o}, h_{r}, h_{s}$ & $\begin{array}{l}\text { total hydraulic head for Ozone, River and } \\
\text { Szone (L). }\end{array}$ & $\gamma_{r}$ \\
\hline$i$ & precipitation intensity $\left(\mathrm{LT}^{-1}\right)$ & $\lambda$ \\
\hline$i_{d c}$ & interception threshold for Czone $\left(\mathrm{LT}^{-1}\right)$. & $\Lambda_{r}$ \\
\hline$K_{s u}, K_{u}$ & $\begin{array}{l}\text { saturated and effective hydraulic conduc- } \\
\text { tivity for Uzone }\left(\mathrm{LT}^{-1}\right) \text {. }\end{array}$ & $\Lambda_{S}$ \\
\hline$K_{s r}, K_{s s}$ & $\begin{array}{l}\text { saturated hydraulic conductivity for } \\
\text { riverbed and Szone }\left(\mathrm{LT}^{-1}\right) \text {. }\end{array}$ & $\Lambda_{u}$ \\
\hline \multirow{2}{*}{$l_{r}$} & length of the river channel (L). & \\
\hline & average cross-sectional area $\left(\mathrm{L}^{2}\right)$. & $\mu$ \\
\hline$n$ & Manning roughness coefficient $\left(\mathrm{TL}^{1 / 3}\right)$. & $\theta_{f}$ \\
\hline \multirow[t]{2}{*}{$P_{r}$} & wetted perimeter of the river cross section & $\rho$ \\
\hline & $(\mathrm{L})$ & $\omega_{o}, \omega_{c}, \omega_{o}$ \\
\hline$Q_{s i}, Q_{o i}, \bar{Q}_{o}$ & $\begin{array}{l}\text { simulated discharge, observed discharge } \\
\text { at the time step i, mean of the observed } \\
\text { discharge }\left(\mathrm{L}^{3} \mathrm{~T}^{-1}\right) \text {. }\end{array}$ & \\
\hline \multirow{2}{*}{$\begin{array}{l}Q_{i+}, Q_{i-} \\
Q_{i m}\end{array}$} & discharges after the parameter perturba- & $\xi$ \\
\hline & after the accepted manual calibration at & $\psi_{b}$ \\
\hline
\end{tabular}

interception flux from Czone, infiltration flux to Uzone, flux between Czone and Ozone $\left(\mathrm{L}^{3} \mathrm{~T}^{-1}\right)$.

tween Ozone and Szone, flux between Ozone and River, flux between Ozone and Czone $\left(\mathrm{L}^{3} \mathrm{~T}^{-1}\right)$.

flux from Czone, percolation flux to Szone $\left(\mathrm{L}^{3} \mathrm{~T}^{-1}\right)$.

flux between Szone and River, flux exchange between the neighbouring REWs, groundwater abstraction $\left(\mathrm{L}^{3} \mathrm{~T}^{-1}\right)$

stream River, flux to the downstrear River $\left(\mathrm{L}^{3} \mathrm{~T}^{-1}\right)$.

the counterpart of $e_{s r}$ and $e_{o r}$.

infiltration capacity $\left(\mathrm{L}^{3} \mathrm{~T}^{-1}\right)$.

gravitational acceleration $\left(\mathrm{LT}^{-2}\right)$.

groundwater abstraction or recharge rate $\left(\mathrm{L}^{3} \mathrm{~T}^{-1}\right)$

total hydraulic head for Ozone, River and

Szone (L).

precipitation intensity $\left(\mathrm{LT}^{-1}\right)$.

interception threshold for Czone (LT $\left.{ }^{-1}\right)$.

saturated and effective hydraulic conduc-

tivity for Uzone $\left(\mathrm{LT}^{-1}\right)$.

saturated hydraulic conductivity for riverbed and Szone ( $\mathrm{LT}^{-1}$ )

length of the river channel $(\mathrm{L})$

average cross-sectional area $\left(\mathrm{L}^{2}\right)$.

wetted perimeter of the river cross section (L).

time step $i\left(\mathrm{~L}^{3} \mathrm{~T}^{-1}\right)$.

$R_{N S}^{2} \quad$ Nash-Sutcliffe efficiency (-).

$R_{N S+}^{2}, R_{N S-}^{2}$, values after parameter perturbation by

$R_{N S m}^{2}, R_{N S}^{2} \quad \pm 50 \%$, and after the accepted manual cal-

ibration (-).

$s \quad$ sink or source term.

$S_{c}, S_{o}, S_{u}, S_{s}$, storage of Czone, Ozone, Uzone, Szone

$S_{r} \quad$ and River (M).

$v_{o}, v_{r} \quad$ velocity of the flow in the River and Ozone $\left(\mathrm{LT}^{-1}\right)$.

$w_{r} \quad$ width of the river channel (L).

$y_{o} \quad$ depth of flow sheet over the overland flow zone surface (L). water depth of the river channel (L). average depth of Szone and Uzone (L). average elevation for river bed, ground surface and soil bottom (L).

average soil depth (L).

scaling factor for Ozone area computation (-).

lumped scaling factor for regional groundwater flow $\left(\mathrm{L}^{2} \mathrm{~T}^{-1}\right)$.

scaling factor for flux exchange between Uzone and Szone (-).

discharge volume percentage bias (-).

relative change in Nash-Sutcliffe efficiency $(-)$.

relative change in percentage bias (-).

average relative error (-).

porosity of the upper and lower soil layer (-).

effective soil porosity of Uzone and Szone (-).

generic thermodynamic property.

average surface slope angle of Ozone in radian.

average slope angle of the channel bed in radian.

soil pore-disconnectedness index (-).

depth of the transition zone of the river bed for the base flow (L).

typical length scale for the exfiltration flux (seepage) (L).

length scale of the wetting front for infiltration $(\mathrm{L})$.

soil pore size distribution index (-).

field capacity of Uzone (-).

water density $\left(\mathrm{ML}^{-3}\right)$.

area fraction of the saturation-excess overland flow domain, infiltration-excess flow domain and the unsaturated flow domain (-).

Darcy-Weisbach friction factor for the channel routing (-).

air entry pressure head at Uzone (L).

Acknowledgements. This research has been funded by the Delft Cluster project Oppervlaktewater hydrologie: 06.03.04. We are very grateful to D. P. Solomatine of UNESCO-IHE for providing the GLOBE optimisation software for automatic calibration. We acknowledge that the data applied in this research were acquired through the project DAUFIN, sponsored by the European Commission within FP5: EVK1-CT1999-00022. S. Brouyère and A. Dassargues of the University of Liège (Belgium) provided the basic data about the geological and hydrogeological conditions of the Geer basin. The Royal Meteorological Observatory (KMI) in Brussels and E. Roulin provided the digital elevation maps and the hydro-meteorological data. The valuable comments provided 
by E. Zehe, an anonymous referee and the editor, M. Sivapalan have considerably improved the manuscript. It is highly appreciated that P. Reggiani provided the original computer code, based on which the numerical model REWASH has been developed.

Edited by: M. Sivapalan

\section{References}

Abbott, M. B., Bathurst, J. C., Cunge, J. A., O’Connell, P. E., and Rasmussen, J.: An introduction to the European Hydrologic System Systeme Hydrologique Europeen, SHE, 1: History and philosophy of a physically based, distributed modelling system, J. Hydrol., 87, 45-59, 1986a.

Abbott, M. B., Bathurst, J. C., Cunge, J. A., O'Connell, P. E., and Rasmussen, J.: An introduction to the European Hydrologic System Systeme Hydrologique Europeen, SHE, 2: Structure of a physically based, distributed modelling system, J. Hydrol., 87, 61-77, 1986b.

Bastidas, L.A., Gupta, H. V., Sorooshian, S., Shuttleworth, W. J., and Yang, Z. L.: Sensitivity analysis of land surface scheme using multicriteria methods, J. Geophys. Res., 104, 19481-19490, 1999.

Bergström, S. and Forsman, A.: Development of a conceptual deterministic rainfall-runoff model, Nordic Hydrol., 4, 147-170, 1973.

Bergström, S.: The HBV model, in: Computer models of watershed hydrology, edited by: Singh, V. P., Water Resources Publications, USA, 443-520, 1995.

Beven, K. J.: Infiltration into a class of vertically non-uniform soils, Hydrol. Sci. J., 29, 425-434, 1984.

Beven, K. J.: Changing ideas in hydrology: the case of physically based models, J. Hydrol., 105, 157-172, 1989.

Beven, K. J.: Prophesy, reality and uncertainty in distributed hydrological modelling, Adv. Water Res., 16, 41-51, 1993.

Beven, K. J.: A discussion of distributed hydrological modelling, in: Distributed hydrological modelling, edited by: Abbott, M. B. and Refsgaard, J. C., Kluwer Academic Publishers, Dordrecht, The Netherlands, 255-278, 1996a.

Beven, K. J.: Response to comments on "A discussion of distributed hydrological modelling” by Refsgaard, J. C. et al., in: Distributed hydrological modelling, edited by: Abbott, M. B. and Refsgaard, J. C., Kluwer Academic Publishers, Dordrecht, The Netherlands, 289-295, 1996b.

Beven, K. J.: Equifinality and uncertainty in geomorphological modelling, in: The scientific nature of geomorphology, edited by: Rhoads, B. L. and Thorn, C. E., John Wily \& Sons, Chichester, UK, 289-313, 1996c.

Beven, K. J.: Towards an alternative blueprint for a physically based digitally simulated hydrologic response modelling system, Hydrol. Process., 16, 189-206, 2002.

Beven, K. and Binly, A.: The future of distributed models: model calibration and uncertainty predication, Hydrol. Process., 6, 279298, 1992

Beven, K. J., Calver, A., and Morris, E.: The Institute of Hydrology distributed model, Institute of Hydrology Report No. 98, UK, 1987.

Beven, K. J., Lamb, R., Quinn, P., Romanowicz, R., and Freer, J.: TOPMODEL, in: Computer models of watershed hydrol- ogy, edited by: Singh, V. P., Water Resources Publications, USA, 627-668, 1995.

Blöschl, G. and Sivapalan, M.: Scale issues in hydrological modelling - a review, Hydrol. Process., 9, 251-290, 1995.

Boyle, D. P., Gupta, H. V., and Sorooshian, S.: Toward improved calibration of hydrologic models: Combining the strengths of manual and automatic methods, Water Resour. Res., 36, 36633674, 2000.

Brooks, R. H. and Corey, A. T.: Hydraulic properties of porous media, Hydrol. Pap. No. 3, Colorado State Univ., Fort Collins, 1964.

Brun, R., Reichert, P., and Künsch H. R.: Practical identifiability analysis of large environmental simulation models, Water Resour. Res., 37, 1015-1030, 2001.

Burnash, R. J. C., Ferral, R. L., and McGuire, R. A.: A Generalized streamflow simulation system - Conceptual modeling for digital computers, US Department of Commerce, National Weather Service and State of Califonia, Department of Water Resources, 1973.

Burnash, R. J. C.: The NWS river forecast system - Catchment modelling, in: Computer models of watershed hydrology, edited by: Singh, V. P., Water Resources Publications, USA, 311-366, 1995.

Calver, A and Wood, W. L.: The Institute of Hydrology distributed model, in: Computer models of watershed hydrology, edited by: Singh, V. P., Water Resources Publications, USA, 595-626, 1995.

Cash, J. R. and Karp, A. H.: ACM Transactions on Mathematical Software, 16, 201-222, 1990.

Doorenbos, J. and Kassam A. H.: Yield response to water, FAO irrigation and drainage paper 33, Food and Agriculture Organisation, Rome, 1979

Dunne, T. and Black, R. D.: Partial area contributions to storm runoff in a small New England watershed, Water Resour. Res. 6, 1296-1311, 1970.

Dunne, T.: Field studies of hillslope flow processes, in: Hillslope Hydrology, edited by: Kirkby, M. J., John Wily \& Sons, Chichester, UK, 227-293, 1978.

Freer, J., Beven, K., and Ambroise, B.: Bayesian estimation of uncertainty in runoff prediction and the value of data: An application of the GLUE approach, Water Resour. Res., 32, 2161-2173, 1996.

Freeze, R. A. and Harlan, R. L.: Blueprint for a physically-based, digitally-simulated hydrologic response model, J. Hydrol., 9, 237-258, 1969.

Grayson, R. B., Moore, I. D., and McMahon, T. A.: Physically based hydrologic modeling, 1, A terrain-based model for investigative purposes, Water Resour. Res., 28, 2639-2658, 1992a.

Grayson, R. B., Moore, I. D., and McMahon, T. A.: Physically based hydrologic modeling, 2, Is the concept realistic?, Water Resour. Res., 28, 2659-2666, 1992b.

Hewlett, J. D. and Hibbert, A. R.: Factors affecting the response of small watersheds to precipitation in humid areas, in: Proceedings of 1st International Symposium on Forest Hydrology, edited by: Sopper, W. E. and Lull, H. W., Pergamon, 275-290, 1967.

Hornberger, G. M. and Spear, R. C.: An approach to the preliminary analysis of environmental systems, J. Environ. Mgmt., 12, 7-18, 1981. 
Kirkby, M. J.: TOPMODEL: A personal view, Hydol. Process., 11, 1087-1097, 1997.

Klemes, V.: Operational testing of hydrological simulation models, Hydrol. Sci. J., 31, 13-24, 1986.

Lee, H., Sivapalan, M., and Zehe E.: Representative Elementary Watershed (REW) approach, a new blueprint for distributed hydrologic modelling at the catchment scale: development of closure relations, in: Predicting ungauged streamflow in the mackenzie river basin: today's techniques and tomorrow's solutions, edited by: Spence, C., Pomeroy, J. W., and Pietroniro, A., Canadian Water Resources Association (CWRA), Ottawa, Canada, 165-218, 2005.

Lindström, G., Johansson, B., Persson, M., Gardelin, M., and Bergström, S.: Development and test of the distributed HBV-96 hydrological model, J. Hydrol., 201, 272-288, 1997.

Nash, J. E. and Sutcliffe, J. V.: River flow forecasting through conceptual models, Part I: a discussion of principles, J. Hydrol., 10, 282-290, 1970.

Newham, L. T. H., Norton, J. P., Prosser, I. P., Croke, B. F. W., and Jakeman A. J.: Sensitivity analysis for assessing the behaviour of a landscape-based sediment and transport model, Environ. Model. \& Soft., 18, 741-751, 2003.

O'Connell, P. E. and Todini E.: Modelling of rainfall, flow and mass transport in hydrological systems: an overview, J. Hydrol., 175, 3-16, 1996.

Press, W. H., Teukolsky, S. A., Vetterling, W. T., and Flannery B. P.: Numerical recipes in C: The art of scientific computing, 2nd Edition, Cambridge University Press, 710-722, 1992.

Refsgaard, J. C. and Storm, B.: MIKE SHE, in: Computer models of watershed hydrology, edited by: Singh, V. P., Water Resources Publications, USA, 809-846, 1995.

Refsgaard, J. C., Storm, B., and Abbott, M. B.: Comment on "A discussion of distributed hydrological modelling" by K. Beven, in: Distributed hydrological modelling, edited by: Abbott, M. B. and Refsgaard, J. C., Kluwer Academic Publishers, Dordrecht, The Netherlands, 279-287, 1996.

Reggiani, P. and Schellekens, J.: Modelling of hydrological responses: the representative elementary watershed approach as an alternative blueprint for watershed modelling, Hydrol. Process., 17, 3785-3789, 2003.

Reggiani, P., Sivapalan M., and Hassanizadeh, S. M.: A unifying framework of watershed thermodynamics: balance equations for mass, momentum, energy and entropy and the second law of thermodynamics, Adv. Water Res., 22, 367-368, 1998.

Reggiani, P., Sivapalan, M., and Hassanizadeh, S. M.: Conservation equations governing hillslope responses: Physical basis of water balance, Water Resour. Res., 38, 1845-1863, 2000.

Reggiani, P., Hassanizadeh, S. M., Sivapalan, M., and Gray, W. G.: A unifying framework of watershed thermodynamics: Constitutive relationships, Adv. Water Res., 23, 15-39, 1999.

Reggiani, P., Sivapalan, M., Hassanizadeh, S. M., and Gray, W. G.: Coupled equations for mass and momentum balance in a stream network: theoretical derivation and computational experiments, Proc. R. Soc. Lond. A(2001), 457, 157-189, 2001.

Reggiani, P. and Rientjes, T. H. M.: Flux parameterization in the Representative Elementary Watershed (REW) Approach: application to a natural basin: Water Resour. Res., 41, W04013, doi:10.1029/2004WR003693, 2005.
Rijtema, P. E. and Aboukhaled A.: Crop water use, in: Research on crop and water use, salt affected soils and drainage in the Arab Republic of Egypt, edited by: Aboukhaled, A., Arar, A., Balba, A. M. et al., FAO, Near East Regional Office, Cairo, 5-61, 1975.

Saltelli, A.: What is sensitivity analysis?, in: Sensitivity analysis, edited by: Saltelli, A., Chan, K., and Scott, E. M., John Wiley \& Sons, Ltd., Chichester, UK, 3-12, 2000.

Savenije, H. H. G.: Equifiniality, a blessing in disguise?, Hydrol. Process., 15, 2835-2838, 2001.

Savenije, H. H. G.: The importance of interception and why we should delete the term evapotranspiration from our vocabulary, Hydrol. Process., 18, 1507-1511, 2004.

Savenije, H. H. G.: Interception, The Encyclopaedia of Water, Wiley, 2005.

Senarath, S. U. S., Ogden, F. L., Downer, C. W., and Sharif, H. O.: On the calibration and verification of two-dimensional, distributed, Hortonian, continuous watershed models, Water Resour. Res., 36, 1495-1510, 2000.

Sivapalan, M., Viney, N. R., and Jeevaraj, C. G.: Water and salt balance modelling to predict the effects of land use changes in forested catchments: 3. The large catchment model, Hydrolog. Process., 10, 429-4446, 1996.

Solomatine, D. P.: Genetic and other global optimization algorithms - comparison and use in calibration problems, in: Proceedings of the 3rd International Conference on Hydroinformatics, Copenhagen, Denmark, Balkema Publishers, 1021-1028, 1998.

Solomatine, D. P.: The use of global random search methods for models calibration, in: Proceedings of XXVIth Congress of the International Association for Hydraulic Research (IAHR), vol. 1, London, 224-229, 1995.

Sorooshian, S., Duan, Q., and Gupta, V. K.: Calibration of rainfallrunoff models: Application of global optimization to the Sacramento Soil Moisture Accounting Model, Water Resour. Res., 29, 1185-1194, 1993.

Strahler, A. N.: Quantitative analysis of watershed geomorphology, American Geophysical Union Transactions, 38, 913-920, 1957.

Tarboton, D. G.: A new method for the determination of flow directions and contributing areas in grid digital elevation models, Water Resour. Res., 33, 309-319, 1997.

Todini, E.: The ARNO rainfall-runoff model, J. Hydrol., 175, 339382, 1996.

Troch, P. A., De Troch, F. P., and Brutsaert, W.: Water table depth to describe initial conditions prior to storm rainfall in humid regions, Water Reour. Res., 29, 427-434, 1993.

Wagener, T.: Evaluation of catchment models, Hydrol. Process., 17, 3375-3378, 2003.

Wagener, T., Wheater, H. S., and Gupta, H. V.: Rainfall runoff modelling in gauged and ungauged catchment, Imperial College Press, London, UK, 2004.

Zehe, E., Lee, H., and Sivapalan, M.: Derivation of closure relations and commensurate state variables for mesoscale hydrological models using dynamical upscaling, in: Predictions in ungauged basins: international perspectives on state-of-the-art and pathways forward, edited by: Franks, S. W., Sivapalan, M., Takeuchi, K., and Tachikawa, Y., IAHS Press, Wallingford, Oxon, UK, in press, 2005.

Zhang, G., Reggiani, P., Rientjes, T. H. M., and Hassanizadeh, S. M.: Modeling rainfall-runoff relation by the Representative Elementary Watershed Approach, in: Proceedings of NCR- 
days 2002: Current themes in Dutch river research, edited by: Leuven, R. S. E. W., van Os, A. G., and Nienhuis, P. H., NCR-publication 20-2003, Netherlands Centre for River Studies, Delft, The Netherlands, 20-22, 2003.

Zhang, G. P., Fenicia, F., Rientjes, T. H. M., Reggiani, P., and Savenije, H. H. G.: Effects of subsurface parameterisation on runoff generation in the Geer basin, in: Proceedings of NCRdays 2003: Dealing with Floods within Constraints, edited by: Douben, N. and van Os, A. G., NCR publication 24-2004, Netherlands Centre for River Studies, Delft, The Netherlands, 68-70, 2004a.

Zhang, G. P., Fenicia, F., Rientjes, T. H. M., Reggiani, P., and Savenije, H. H. G.: Application and development of a catchmentscale rainfall-runoff model using the REW approach, Geophys. Res. Abstr., 6, EGU04-A-01583, European Geosciences Union, SRef-ID: 1607-7962/gra/EGU04-A-01583, 2004 b.
Zhang, G. P., Fenicia, F., Rientjes, T. H. M., Reggiani, P. and Savenije, H. H. G.: Modeling runoff generation in the Geer River Basin with improved model parameterizations to the REW approach, Phys. Chem. Earth, 30, 285-296, 2005a.

Zhang, G. P., Savenije, H. H. G., Fenicia, F., Rientjes, T. H. M., and Reggiani, P.: Implications of hydrological modelling and observations in the Alzette river basin, in: Proceedings of NCR-days 2004: Research for managing rivers; present and future issues, in press, 2005b. 